\title{
EFFECT OF MOTIVATIONAL INCENTIVES ON FACE-NAME HYPER-BINDING IN OLDER ADULTS
}

\author{
By \\ Liyana T. Swirsky, Bachelor of Science (Hons.) \\ University of Guelph, 2014 \\ A thesis \\ presented to Ryerson University \\ in partial fulfillment of the \\ requirements for the degree of \\ Master of Arts \\ in the program of \\ Psychology
}

Toronto, Ontario, Canada, 2018

(C) Liyana T. Swirsky 2018 


\section{AUTHOR'S DECLARATION FOR ELECTRONIC SUBMISSION OF A THESIS}

I hereby declare that I am the sole author of this thesis. This is a true copy of the thesis, including any required final revisions, as accepted by my examiners.

I authorize Ryerson University to lend this thesis to other institutions or individuals for the purpose of scholarly research.

I further authorize Ryerson University to reproduce this thesis by photocopying or by other means, in total or in part, at the request of other institutions or individuals for the purpose of scholarly research.

I understand that my thesis may be made electronically available to the public. 


\begin{abstract}
Master of Arts, 2018

Liyana T. Swirsky

Psychology

Ryerson University
\end{abstract}

Effect of Motivational Incentives on Face-Name Hyper-Binding in Older Adults

Hyper-binding refers to the tendency for older adults to encode extraneous information from their environment, and bind this information to attentional targets such that this distracting information can be remembered in association with target information on a subsequent task. This tendency is hypothesized to result from a loss of selectivity in memory and attention due to a loss of inhibitory control. However, older adults do demonstrate selectivity under certain motivational conditions. For example, older adults show enhanced memory selectivity in rewardmotivated states. The current study used motivational incentives (virtual rewards) to investigate the interaction between hyper-binding and reward-based motivation. Results revealed a motivation-related decrease in hyper-binding in older adults. This decrease was not affected by incentive magnitude (low versus high). These results suggest that the value-directed selectivity of memory and attention counteract the age-related selectivity deficit associated with hyperbinding.

Keywords: Cognitive aging, inhibitory control, selective attention, hyper-binding, motivated cognition, reward-based motivation 


\section{Acknowledgements}

First and foremost, I would like to thank my supervisor, Dr. Julia Spaniol, for her integral role in conceptualizing, designing, and revising this thesis project. I would also like to thank Dr. Lixia Yang for her thoughtful comments and revisions at the proposal stage as well as for the final product. Thanks also to Dr. Todd Girard for serving on my committee as examiner and providing helpful insight and new perspectives on the project and to Dr. Meg Moulson for chairing my defense and providing ideas for future directions. A final thanks to MAD lab members, my family, and friends for their endless support and to whom I owe my sanity throughout the completion of this project. 


\section{Table of Contents}

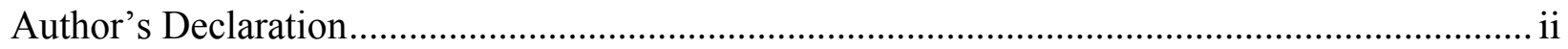

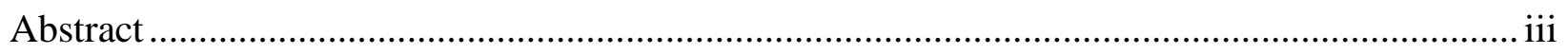

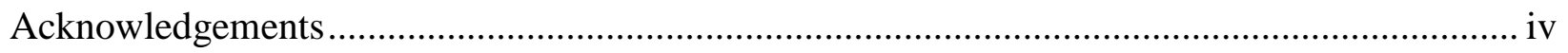

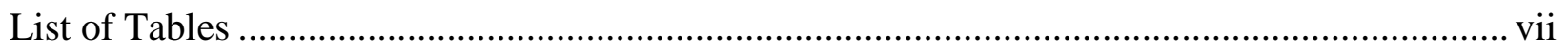

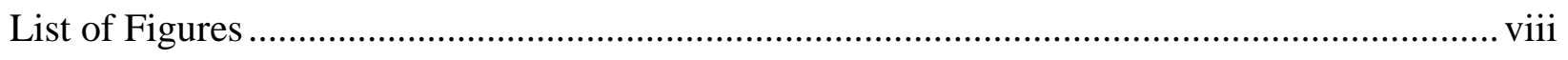

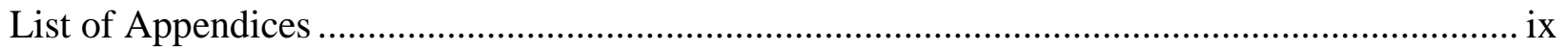

Chapter 1: Introduction and Theoretical Background ............................................................ 1

1.1 Inhibitory Control and Selectivity ................................................................................. 1

Inhibitory control. .......................................................................................................... 1

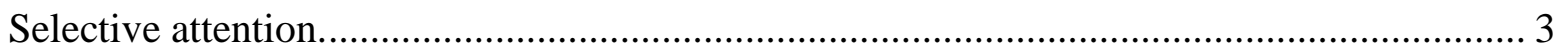

Age-differences in inhibitory control and selective attention. ............................................. 3

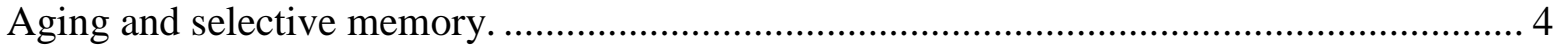

1.2 Hyper-binding ....................................................................................................... 5

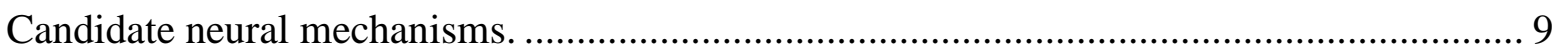

1.3 Aging, Motivation, and Selectivity ………………....................................................... 10

Age differences in motivation and selective attention........................................................... 10

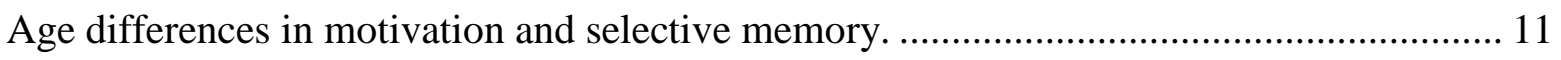

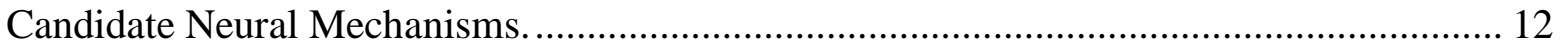

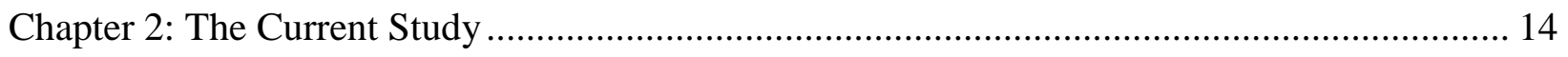

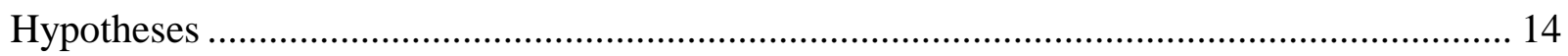

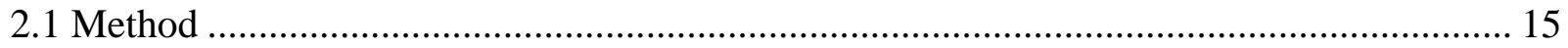

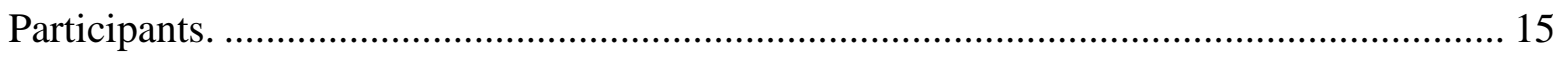

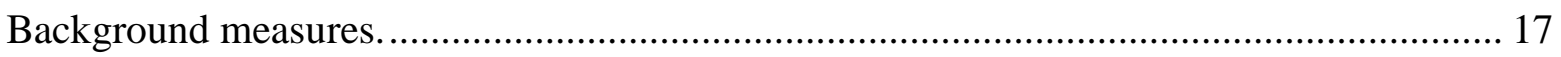

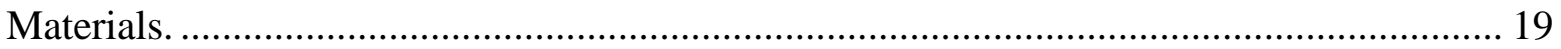

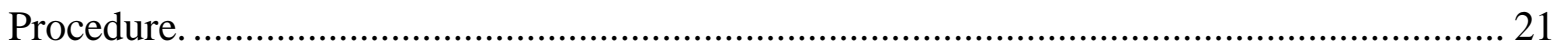

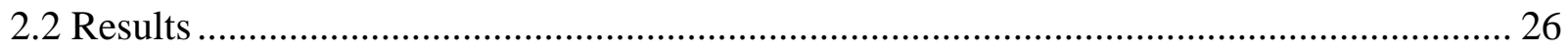

Background Measures. .............................................................................................. 26

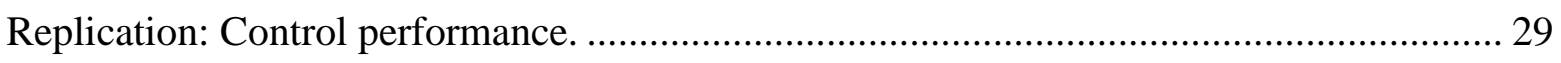

Motivation \& Hyperbinding: Control vs. motivated performance........................................ 30

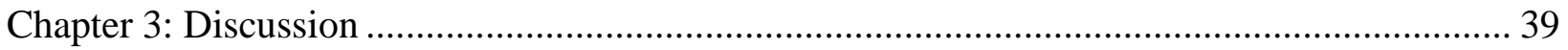




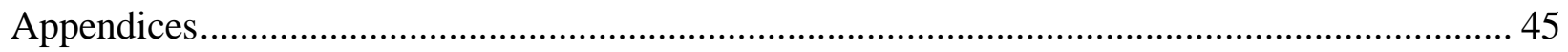

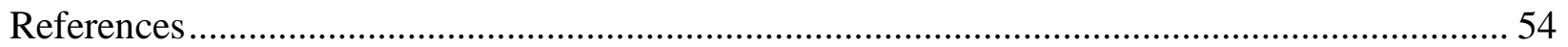




\section{List of Tables}

Table 1: Group characteristics................................................... 18

Table 2: 1-back performance as a function of age group and experimental condition.............30

Table 3: Recall performance as a function of age group and experimental condition............32

Table 4: Arousal and valence ratings as a function of age group and experimental condition....34

Table 5: 1-back performance as a function of age group and incentive level in the motivated

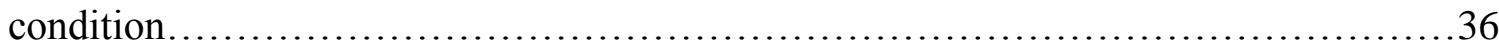

Table 6: Recall performance as a function of age group, pair type and incentive level in the motivated condition.............................................................. 37 


\section{List of Figures}

Figure 1: Face stimuli samples................................................ 19

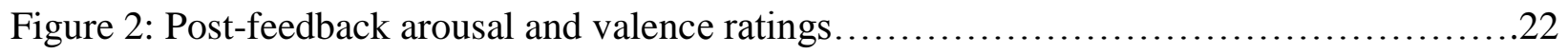

Figure 3: Schematic of the different types of 1-back tasks.............................24

Figure 4a: Reaction times for the 1-back task as a function of age group and experimental condition.

Figure 4b: Accuracy for the 1-back task as a function of age group and experimental condition

Figure 5: Recall as a function of age group and pair type................................ 33

Figure 6: Ratings of arousal and valence as a function of age group and block type............34

Figure 7a: Reaction times for the 1-back task as a function of age group and pair type in the motivated condition....................................................... 36

Figure 7b: Accuracy for the 1-back task as a function of age group and pair type in the motivated

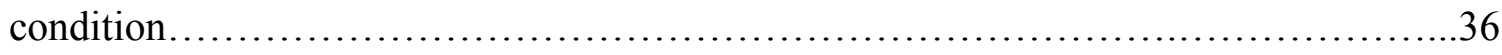

Figure 8: Recall as a function of age group, pair type and incentive level....................37 


\section{List of Appendices}

Appendix A: Demographics.................................................... 45

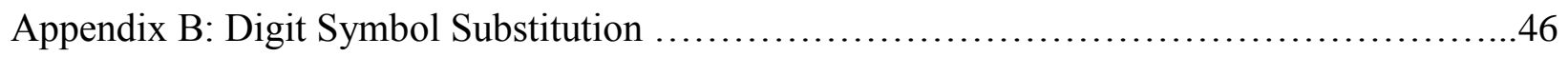

Appendix C: Digit Span...................................................... 47

Appendix D: Mill Hill Vocabulary Scale ..............................................48

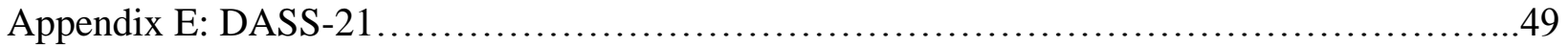

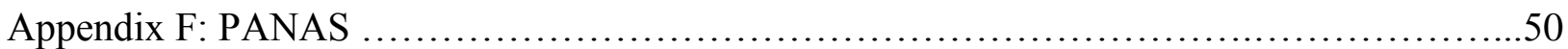

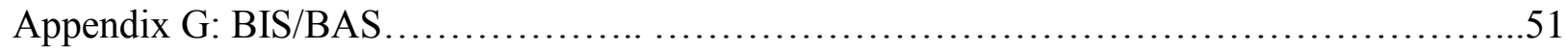

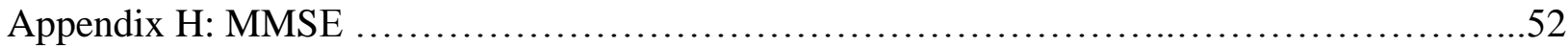

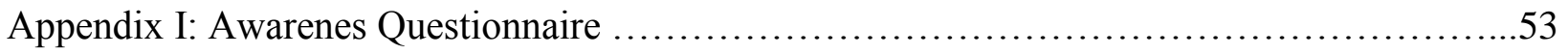


Effect of Motivational Incentives on Face-Name Hyper-Binding in Older Adults

\section{Chapter 1: Introduction and Theoretical Background}

Aging is associated with a decline in the cognitive ability to inhibit irrelevant stimuli when attending to one's environment (Hasher, Stoltzfus, Zacks, \& Rypma, 1991). This ability, known as inhibitory control, is implicated in attentional processes as it enables selectivity. Selective attention at encoding facilitates selective memory on subsequent tasks. Thus, older adults are more likely than younger adults to encode irrelevant environmental stimuli alongside target stimuli and remember this distractor information later on (Rowe, Valderrama, Hasher, \& Lenartowicz, 2006). Recent findings suggest that this irrelevant information is not only remembered alone but that it is bound to the target information such that older adults recall target-distractor associate pairs (Campbell, Hasher, \& Thomas, 2010). The age-related tendency to encode and bind distractor information to attended targets has been labelled hyper-binding. Paradoxically, other literature suggests that memory selectivity in older adults remains intact under the right motivational circumstances. For example, older adults selectively remember highly-valued information (Castel et al., 2016), emotionally-valenced information (Spaniol, Voss, \& Grady, 2008), or information encountered in close proximity to reward (gains) or punishment (losses; Spaniol, Schain, \& Bowen, 2014). The current study attempted to reconcile conflicting findings by incentivizing a typical hyper-binding paradigm with virtual rewards. Will the age-related hyper-binding effect persist when encoding occurs in the context of rewardmotivated states?

\subsection{Inhibitory Control and Selectivity}

Inhibitory control. The purpose of inhibitory control as an attentional mechanism is to ensure that target stimuli are the central focus of working memory, while irrelevant stimuli are 
suppressed, and to ensure that a voluntary response outcompetes a prepotent response (Rowe et al., 2006). Hasher, Zacks, and May, (1999) referred to these functions as access, deletion, and restraint, respectively. These mechanisms of top-down inhibition are implicated in many cognitive tasks used in experimental psychology, such as the Stroop task ( Stroop, 1935; West \& Alain, 2000 Amer \& Hasher, 2014), Flanker task (Eriksen \& Eriksen, 1974; R. S. Williams, Kudus, Dyson, \& Spaniol, 2017), and response inhibition paradigms such as go/no-go and stopsignal tasks (Gomez, Ratcliff, \& Perea, 2007; B. R. Williams, Ponesse, Schachar, Logan, \& Tannock, 1999).

While the n-back task is traditionally used as a measure of working memory (Redick \& Lindsey, 2013), it can be modified to include distractor stimuli such that it also requires interference resolution between the target (attended stimulus that cues response when it repeats) and the distractor (an unattended, superimposed stimulus that must be ignored; Amer \& Hasher, 2014; Biss \& Hasher, 2011; Biss, Ngo, Hasher, Campbell, \& Rowe, 2013; Campbell et al., 2010; Rowe et al., 2006; Weeks, Biss, Murphy, \& Hasher, 2016). This way, the n-back task necessitates inhibitory control similar to the requirements of a Flanker task, wherein participants must suppress distraction from the flanking arrows and respond only to the central arrow

For the purposes of this thesis, inhibitory control refers to the first two functions of access and deletion. Depending on the current goal, inhibitory control acts to focus attention upon a target stimulus while inhibiting irrelevant stimuli that remain in one's visual field in order to limit active representations to goal-relevant stimuli and suppress competing stimuli that are not currently relevant (Diamond, 2013; Hasher, Lustig, \& Zacks, 2008). The narrowed attention that results from efficient inhibitory control (including both access to targets and deletion of distractors) will henceforth be called selective attention. 
Selective attention. Cognitive control—-the mechanism through which we establish goaldirected changes in information processing (Braver, 2012)—encompasses both inhibitory control and resultant selective attention. As mentioned above, inhibitory control can be thought of as an attentional mechanism that enables selectivity (Hasher \& Zacks, 1988). Selective attention is a type of cognitive control strategy that allows individuals to hone in on important information, facilitating encoding of said-information (Mather \& Carstensen, 2005). A function of attention, in general, is to prioritize information for perceptual processing. Therefore, selective attention acts to relay attended information to processing centers. In this way, selective attention can be thought of as a "filter" that only allows passage to particular stimuli (Cowan, 1988; Logan, 2002). For example, by attending to a picture on a screen we are facilitating the conceptual processing of that picture, while an unattended word on the same screen may go unprocessed or only reach abstract levels of processing (Amer \& Hasher, 2014; Tipper \& Driver, 1988). However, due to a decrease in inhibitory control, older adults appear to attend to distractors and submit them to further processing as is done with target information. Age differences such as this have been relatively robust in cognitive aging literature and will be discussed in the next section.

Age-differences in inhibitory control and selective attention. As alluded to above, there is a well-documented decrease in inhibitory control with age (Giesen, Eberhard, \& Rothermund, 2015; Hasher et al., 1991; Pettigrew \& Martin, 2014); consequently, there is also an age-related loss of attentional selectivity (James, Strunk, Arndt, \& Duarte, 2016). The inhibitory deficit hypothesis (IDH) suggests that age-related differences in cognitive function (e.g., working memory) can be explain by reduced inhibition, or inhibitory control, in older adults (Hasher et al., 1991; Hasher \& Zacks, 1988) . According to the IDH, reduced inhibition is a primary age-related deficit that makes older adults more likely to attend to irrelevant stimuli 
and process this information to some degree. The loss of inhibitory control, and associated loss of selectivity of visual attention and memory, ultimately renders older adults more distractible than younger adults (Hasher et al., 1991). To reiterate, selective attention is achieved by both attending to a target stimulus and ignoring (or inhibiting) the distractor stimuli. Older adults are worse are inhibiting distractors but research suggests that they can still select targets (Hasher et al., 1991). This selection process, however, is less efficient than what is seen in younger adults, as older adults are thought to maintain more active representations in working memory at any given moment (Hamm \& Hasher, 1992; Hasher, Quig, \& May, 1997; Hasher \& Zacks, 1988).

As predicted by the IDH, there are many downstream consequences of compromised inhibitory control and attentional selectivity (Lustig, Hasher, \& Zacks, 2007). The most relevant to the current investigation are an increase in awareness of and access to irrelevant information. A lack of inhibition affects early attentional processes at encoding, which has implications for what is later remembered. Therefore, this theoretical framework presupposes age differences in memory selectivity (Lustig et al., 2007).

Aging and selective memory. Selectivity can also be contextualized in a mnemonic framework. Memory is guided by attention to the extent that we are more likely to remember items that we attend to during encoding. Thus attentional biases may lead to memory biases (Mather \& Carstensen, 2003). Selectively attending to a stimulus promotes encoding (Logan, 2002) of that stimulus which in turn increases the probability that this information can later be recalled. Therefore, if distracting stimuli are effectively ignored, it is expected that we do not deeply encode this information (Cheke, 2016). The age-related reduction in inhibitory control has been linked to the tendency to encode distractor information, and a priming effect whereby distractor information is more easily accessed on subsequent implicit (Geraci, 2006; Rowe et al., 
2006) or explicit (Biss et al., 2013; Weeks \& Hasher, 2016) memory tasks. In other words, because older adults are not as effective as younger adults at filtering out distracting stimuli, they may incidentally encode irrelevant information, as evidenced by implicit (e.g., word-stem completion) or explicit (e.g., cued recall) knowledge of the prior distractors on subsequent tasks. For example, when told to focus on pictures and ignore superimposed distractor words, older adults showed a reduced ability to ignore the words compared to younger adults. In fact, distractor words were encoded and older adults showed better implicit memory for distractor words on a subsequent word-completion exercise than younger adults (Rowe et al., 2006).

\subsection{Hyper-binding}

The deficits in inhibitory control and reduced selective attention seen with age set the stage for older adults to hyper-bind target and distractor stimuli. This refers to the tendency to encode and bind distractor information to target information, such that these target-distractor associations are available in memory for later recall (Campbell et al., 2010). This age-related phenomenon has been theorized to include 4 stages: 1) Older adults fail to inhibit distractor information presented with target information; 2) Older adults encode distractor information alongside target information; 3) Older adults bind distractor information to target information; 4) This bound information can be accessed on a subsequent memory task (Campbell et al., 2010).

Hyper-binding was first described in 2010, when Campbell et al. demonstrated that older adults, but not younger adults, showed a recall advantage for picture-word associates that had previously been encountered together during an "unrelated" 1-back task. Older adults completed a 1-back task in which they were told to attend to the pictures (targets) and ignore the superimposed words (distractors). This was the incidental encoding stage. Subsequently, participants were given a list of picture-word pairs that they were told to learn. Some of these 
pairs were "maintained" (seen together during the 1-back task), while others were "disrupted" (seen separately during the 1-back task). Only older adults showed a memory advantage for maintained pairs, while younger adults showed similar recall rates across pair-type. The Age $\mathrm{x}$ Pair-type interaction indicated that older adults not only encoded distractor words during the 1back, but that they formed associations between simultaneously presented distractor and target stimuli.

These findings have been replicated using the same basic paradigm with different stimuli. For example, older adults also demonstrate hyper-binding of pairs of unrelated words that were encountered together in the initial encoding phase, or rearranged pairs that were shuffled using words that were encountered in close spatial/temporal proximity during encoding (Campbell, Trelle, \& Hasher, 2014). For older adults, implicit memory of word pairs that were identical or were seen closer together on the encoding list was better than for word pairs that were rearranged using temporally/spatially-distant words. This phenomenon also holds true when the target and distractor stimuli are meant to be associated. As an example, older adults hyper-bind target face stimuli with distractor names (Weeks et al., 2016), exemplifying a situation in which hyperbinding may be adaptive (i.e., when distractor information is likely to become relevant later on). After studying a list of face-name pairings, older adults showed better explicit recall for names of faces that were also encountered together during the incidental encoding phase (the 1-back task).

The notion that hyper-binding results from a lack of attentional selectivity (due to a lack of inhibitory control) is consistent with studies that use additional manipulations to broaden participants' attentional scope. One such technique used to broaden attention is positive mood induction (Fredrickson, 2004). When subjected to this manipulation using positively valenced picture primes, younger adults performed more like older adults such that they exhibited better 
implicit memory for distractors (Biss \& Hasher, 2011). Whether younger adults actually formed associations between targets and distractors from the 1-back task in this broadened attentionalstate was not examined, but is an area for future research.

In order for the hyper-binding effect to occur, there must be transfer of both the distractor and the distractor-target pair to a subsequent memory task. This effect has been exhibited in older adults using different stimulus types (e.g., line drawings, pictures, words, names), different contextual manipulations (e.g., spatial distance, temporal distance), as well as across both implicit and explicit tests of memory (e.g., word-stem completion, cued recall; Biss \& Hasher, 2011; Biss et al., 2013; Campbell et al., 2014; Campbell, Zimerman, Healey, Lee, \& Hasher, 2012; Weeks et al., 2016). Overall, results from this literature indicate that, relative to younger adults, older adults are worse at suppressing distractor stimuli, are liable to bind distractors to targets, and have access to distractor information (alone or in association with a target) on subsequent tasks

This phenomenon is interesting against the backdrop of the associative deficit hypothesis $(\mathrm{ADH})$, an influential hypothesis in the cognitive-aging literature. According to the ADH (Naveh-Benjamin, 2000), aging is accompanied by a deficit in associative memory, specifically. While this may be true of explicit episodic memory processes, hyper-binding points to better-or over-active—implicit associative memory processes (Campbell, 2010; Campbell, Trelle, \& Hasher, 2014).

Indeed, a recent study (Campbell and Hasher; 2018) underscored the implicit nature of hyper-binding. The authors demonstrated that under explicit conditions, when older adults were alerted to the connection between the incidental encoding 1-back and the memory task, they no longer demonstrated the hyper-binding effect. Younger adults, on the other hand, did not exhibit 
the hyper-binding effect in either awareness condition. Along with confirming the implicit nature of this phenomenon, this age difference implicates encoding as the relevant stage of processing for hyper-binding rather than retrieval.

Equally important to understanding the conditions under which hyper-binding occurs is identifying conditions under which it does not occur. Along with explicit awareness, other limits to age-related hyper-binding have recently been suggested. Using an attribute amnesia paradigm, McCormick-Huhn, Chen, Wyble, and Dennis (2017) tested whether hyper-binding generalizes to irrelevant information that was once relevant. Participants performed a task in which they had to report the location of a letter after viewing a screen with one letter plus three distracting numbers. Letters were task-relevant until their location was processed, after which they lost their relevance. In other words, for the task at hand, participants only needed to hold letter-location in mind but not letter identity. However, surprise trials that required participants to identify the letter from the previous screen tested working memory for these freshly irrelevant targets. The hyper-binding theory would predict an age-related advantage on the surprise test, as older adults are expected to hyper-bind letter identity to letter location. However, like younger adults, older adults failed to bind letter attributes (identity and location) and performed poorly on surprise trials of letter identification. To this end, hyper-binding may not apply to "de-selected" previously-relevant information. The lack of an age difference here suggests that the deletion function of inhibition is relatively spared with age, further implicating the access function of inhibitory control (Hasher et al., 2008)as an underlying mechanism for age-related hyperbinding.

Along these lines, and of particular significance to the current investigation, are boundaries related to value-directed encoding. Counter to predictions from the theory of hyper- 
binding, Hennessee, Knowlton, and Castel (2018) showed a value-related reduction in recall for task-irrelevant details (i.e., the colour of the target word) for older adults and younger adults. Moreover, older adults demonstrated less binding than younger adults when retrieving context details about valuable items. While these findings appear to be incompatible with the theoretical framework of hyper-binding, it is possible that value-directed increases in attentional selectivity mask the hyper-binding effect. This possibility contributed to the rationale for the current study.

Candidate neural mechanisms. Aging is associated with reduced activity in frontoparietal regions during encoding (Amer \& Hasher, 2014; Campbell et al., 2012), which has been linked to increased processing of distractor information (or less efficient inhibitory control). The frontoparietal network is thought to encompass areas and connections crucial for selective attention (Ptak, 2012) as it is consistently activated during attention-based tasks (Braver et al., 2014). Despite a decrease in frontoparietal activity overall, older adults have shown stronger functional connectivity between the frontoparietal control network and dorsal posterior cingulate cortex (dPCC), which may serve a compensatory function (Campbell, Grigg, Saverino, Churchill, \& Grady, 2013). Indeed, older adults with greater frontoparietal activity have also shown more intact selective memory such that they form more accurate/relevant associations while those with less activity form incorrect/irrelevant associations (Devitt \& Schacter, 2016). Age differences in this neural network-given its relevance to changes in selective attention and memory—may help to explain age-related hyper-binding.

Another region often implicated in cognitive aging is the prefrontal cortex (PFC) due to its association with the midbrain dopaminergic system (Braver et al., 2014). Age is associated with shrinking of the PFC as well as a loss of dopaminergic projections (Braver \& Barch, 2002). Along with cognitive control and selective attention (Braver, 2012; Devitt \& Schacter, 2016; 
Mather \& Carstensen, 2005), activation in the dorsolateral PFC has been linked to depth of encoding (Cheke, 2016); this is consistent with the finding that older adults are not only more likely to encode distractors, but that they are less efficient at encoding targets (Geraci, 2006; Hasher et al., 1991). Thus, the age-related changes in the prefrontal cortex may also help to explain hyper-binding-related decreases in selectivity of memory and attention.

\subsection{Aging, Motivation, and Selectivity}

There are many sources of appetitive motivation. Two major motivational drives addressed in the cognitive aging literature are the motivation to attain/maintain positive affect, as well as the motivation to obtain some kind of reward/incentive. The age differences in these motivation-based effects on cognitive processes will be discussed in the following sections.

Age differences in motivation and selective attention. According to the socioemotional selectivity theory (SST), older adults are motivated to optimize their well-being as opposed to the achievement orientation seen in younger adults (Carstensen et al., 1999; Carstensen, Fung, \& Charles, 2003). This socioemotional shift promotes selective attention to information consistent with their goal of emotion-regulation (Mather \& Carstensen, 2003). Over the past decade, efforts to test predictions of the SST have found age differences in information processing biases, collectively referred to as the positivity effect (Carstensen \& DeLiema, 2018; Reed \& Carstensen, 2012). That is, because of their emphasis on socioemotional well-being, older adults have a top-down attentional bias for positive information relative to neutral, and negative information (Mather \& Carstensen, 2005). For example, older adults showed attentional bias for positive faces inferred from their shorter response time (RT) when responding to dots that appeared beneath positive faces versus dots appearing under neutral or negative faces. Younger adults, on the other hand, did not reveal a positivity bias, with an equally fast RT associated with 
negative faces. In a similar study using fMRI, greater activity in the amygdala was associated with viewing the positive faces at encoding, compared to negative or neutral faces, in older adults. The opposite was true for younger adults (Mather et al., 2004). This selectivity for positive information is contrasted by the lack of selectivity associated with positive states. As mentioned above, positive mood decreases inhibitory control and is associated with decreased suppression of distractor information (Biss \& Hasher, 2011; Mather \& Schoeke, 2011). Thus, a positive mood can weaken inhibitory control in younger and older adults, but older adults carry a general bias_-or selectivity_-for positive information.

While older adults and younger adults differ in their attention to information based on valence (i.e., positive or negative), they both exhibit sensitivity to the value of information or potentially rewarding circumstances. The preserved selectivity for differentially valued information or reward-motivated tasks will be discussed in more depth in the next section.

Age differences in motivation and selective memory. Age-related differences in goals (as predicted by the SST) establish differential motivation, and age-related differences in what we attend to (based on our current goals) predict age-differences in what we remember. Thus the age-related positivity effect, or the cognitive bias for positive information, is not limited to attention but also influences age differences in memory (Reed, Chan, \& Mikels, 2014). For example, older adults are more likely to remember or be more familiar with positive information, such as positive faces, which they were biased to attend in the first place (Mather \& Carstensen, 2003). Older adult's proclivity toward emotional goals leads to emotionally-directed memory, such that — in laboratory settings_ - positively-valenced stimuli are better remembered by older than younger adults (Spaniol et al., 2008). This emotional bias can also be extended to autobiographical memory retrieval. That is, older adults remember more positive aspects of their 
past and remember past choices as more positive than alternatives not chosen relative to younger adults (Q. Kennedy, Mather, \& Carstensen, 2004; Mather \& Carstensen, 2005). Consistent with the SST, this goal-directed alteration in memory reflects the greater importance that older adults attribute to emotion-regulation.

When it comes to reward-motivated memory, the age differences are less pronounced or non-existent. Older adults demonstrate relatively intact memory (encoding and retrieval) selectivity for valuable information (Castel et al., 2016; Castel, Benjamin, Craik, \& Watkins, 2002; Cohen, Rissman, Suthana, Castel, \& Knowlton, 2014), or information encountered during reward-motivated states (Spaniol et al., 2014). For example, older adults actually exhibited greater selectivity in short-term recall for highly-valued items (items that were arbitrarily paired with higher point value) than did younger adults (Castel et al., 2002); this performance difference was hypothesized to reflect better control strategies in older adults at encoding. Likewise, older adults show relatively intact associative memory for highly-valued face stimuli; like younger adults, older adults exhibited better cued-recall rates when recalling the highest values associated with face stimuli at encoding (Castel et al., 2016). Similarly, older adults show improved intentional encoding of pictures for stimuli associated with the anticipation of high reward; importantly, the encoding itself was not rewarded but occurred in the context of potential for reward (Spaniol et al., 2014). It is less understood, however, how the presence of high values or reward affects the automatic_ or incidental—encoding of target stimuli. The current study addressed this gap in the literature.

Candidate Neural Mechanisms. There are a variety of regions implicated in age-related changes in motivated cognition. Considering the shift in goals across the lifespan described by the SST, it is not surprising that the amygdala — the emotional processing center - remains intact 
with aging (Braver et al., 2014; Mather \& Carstensen, 2005). Similarly, patterns of responsiveness of the reward-network (midbrain, striatal, and insular regions involved in reward anticipation) undergo little change from younger to older adulthood, which is consistent with the similar effects of reward expectation on memory seen in younger and older adults (Spaniol, Bowen, Wegier, \& Grady, 2015). In contrast, an area that undergoes substantial functional changes is the PFC (Grady, 2008). Upregulation of this region in OA has been linked to cognitive control in the face of motivational incentives (Braver, 2012; Spaniol et al., 2015); thus, a greater prefrontal decline (with an accompanying decrease in cognitive control) may underlie the attentional bias for positive information seen in older adults (Mather \& Carstensen, 2005). Despite proposals that the positivity effect is due to neural degradation (Cacioppo, Berntson, Bechara, Tranel, \& Hawkley, 2011) or cognitive decline (Labouvie-Vief, Grühn, \& Studer, 2010), Mather and Knight (2005) showed that older adults with higher levels of cognitive functioning demonstrated a greater positivity bias for positively-valenced pictures. Likewise, when compared to Alzheimer patients, Kalenzaga, Lamidey, Ergis, Clarys, and Piolino (2016) demonstrated that only healthy older adults showed a positivity effect in emotional memory.

More recently, motivational changes across the lifespan have been linked to changes in the locus-coeruleus (LC), the primary source of norepinephrine (NE) in the brain (Mather \& Harley, 2016). Traditionally, the LC-NE system has been associated with arousal while dopaminergic systems have been associated with motivation (Braver et al., 2014; Chiew \& Braver, 2011). However, arousal plays a crucial role in activating cognitive and behavioural responses; thus, it is conceivable that both neural systems are relevant to reward-motivated action (Braver et al., 2014). Further research is needed to better characterize the unique contributions of dopaminergic and noradrenergic networks to motivation and cognitive aging. 


\section{Chapter 2: The Current Study}

Presently, no research has examined the effects of incentive-based motivation on hyperbinding-related age-differences in memory. The current study seeks to address uncertainty surrounding the conditions under which hyper-binding occurs by testing the interaction between hyper-binding and reward-based motivation. Specifically, can the hyper-binding phenomenon be moderated by motivation states (induced using virtual incentives) at encoding? This study used a biphasic paradigm typical of hyper-binding studies, consisting of an initial 1-back task (facename incidental encoding) and memory phase (intentional face-name learning).

The study included two conditions. The purpose of the control condition was to replicate the age-related hyper-binding effect reported in the literature (Campbell et al., 2010, 2014; Weeks et al., 2016), and to serve as a between-subjects control condition for the motivation manipulation used in the motivation condition. The motivation condition was identical to the control, but with the introduction of the novel incentive manipulation. The dependent variables were measures of performance on the 1-back task and memory test. For the 1-back task, performance was measured with respect to reaction time (RT, ms) and accuracy (hit rate minus false alarm rate). For the memory test, performance was measured in terms of recall success (reporting the correct name when cued with a face). The independent variables were condition (1 [non-motivated control], 2 [motivated]), age group (younger adult, older adult) and pair-type (maintained, rearranged). For the motivated condition, an additional independent variable was block type (low-gain, high-gain).

\section{Hypotheses}

As mentioned above, the control condition was expected to replicate the results of Weeks et al (2016). Related to the objective of replication, the hypotheses were: 1) younger and older 
adults would be similarly accurate on the 1-back task (no main effect of age on accuracy during the encoding phase); 2) younger adults were expected to correctly recall more names overall (main effect of age on memory phase accuracy); 3) Unlike younger adults, older adults were expected to show a memory advantage for names studied from maintained versus rearranged face-name pairings, the pattern of recall which operationalizes the hyper-binding effect (Age $\mathrm{x}$ Pair-type interaction; older, but not younger, adults would have higher accuracy for maintained versus rearranged pairs); 4) Younger adults were expected to be faster than older adults on the 1back task (main effect of age on RT during the encoding phase)—although reaction time results were not reported by Weeks et al. (2016), this would replicate findings from the original hyperbinding study (Campbell et al., 2010).

Related to the effect of motivation on hyper-binding, there were two main hypotheses that were tested: 1) Older adults in the motivated condition) would hyper-bind less than older adults in the control condition (Age x Pair-type $\mathrm{x}$ Condition interaction; the age-related recall advantage for maintained pairs would be more pronounced in the control than the motivated condition); 2) In the motivated condition, hyper-binding would be more pronounced for maintained pairs originating from low-gain relative to high-gain blocks (Age x Pair-type x Block-type interaction such that older, but not younger, adults remember more maintained than rearranged, however this recall advantage would depend on the level of incentive). In other words, high level incentive was expected to reduce hyper-binding. As such the older adult group from condition 1 served as between-subject control group, and the low-gain incentive blocks served as a within-subject control condition.

\subsection{Method}

Participants. The study included 96 participants, a sample size which was based on results of power analysis run via G-Power (Faul, Erdfelder, Lang, \& Buchner, 2007) to achieve a 
power of at least .95 to detect a medium-sized interaction of a between-subjects factor and a within-subjects factor, assuming an alpha error probability of .05 and a correlation among levels of the within-subjects factor of .30 or higher. The control condition included 48 participants; 24 healthy younger adults (ages 18-34 years, $M=25.0, S D=4.8 ; 16$ female) and 24 healthy older adults (60-85 years, $M=67.4, S D=6.3 ; 16$ female). Similarly, the motivation condition included 24 healthy younger adults (aged 18-33 years, $M=23.0, S D=4.4 ; 16$ female) and 24 healthy older adults (aged 61-87 years, $M=67.5, S D=6.8 ; 16$ female).

Younger adults were recruited from the community via advertisement and word-of-mouth and older adults were recruited from the Ryerson Senior Participant Pool (RSPP). Participants received \$12 compensation for their participation in the study. Participants in the motivation condition were also awarded virtual points earned from the reward-motivated 1-back task. Cumulative reward ranged from a minimum 6,857 points to a maximum of $11,192(M=$ $8,862.42, S D=977.94)$. Both younger and older adults underwent basic eligibility screening via telephone before participation. The phone-based screening questionnaire addressed demographics (e.g., age, gender, education, language, etc.), vision, audition, as well as medical history and health conditions including cardiovascular and psychiatric disorders (see Appendix A). Participants did not meet eligibility criteria if they reported diagnosed psychiatric illness, use of psychiatric medication, learning disability, untreated cardiovascular or thyroid disorder, cancer (last 3 years), or past head injury (including concussion). Exclusion criteria for eligible participants were as follows: scoring $<26$ on Folstein, Folstein, and McHugh's (1975) MiniMental State Examination (MMSE; described below), reporting an awareness of the connection between tasks at the end of the experiment, or scoring "extremely severe" on any of the subscales of the Depression, Anxiety, and Stress Scale-21 (DASS-21; Lovibond \& Lovibond, 
1995, described below; $n=1$ ). One older adult participant was excluded and replaced for an extreme score on the Depression sub-scale of the DASS-21.

Younger adults in the control condition did not significantly differ in age from those in the motivated condition $(p=.15)$. Likewise, older adults in the control condition were matched on age with those in the motivated condition $(p=.97)$. Moreover, the levels of education in either condition were not significantly different between age groups (control: $p=.27$; motivated: $p=.22$ ). Summary statistics for age and education in control and motivated younger and older adults are listed in Table 1.

Background measures. During the 20-minute interval between the two computer-based tasks of the experiment, participants were assessed on seven different baseline measures (see appendices B-H). The digit symbol substitution test (WAIS-III; Wechsler, 1997) was used to assess processing speed. The digit span (forwards and backwards) was administered to assess verbal working memory (WAIS-R; Weschler, 1981). Verbal intelligence was probed via the Mill-Hill Vocabulary scale (MHV; Raven, 1982). The DASS-21 (Lovibond \& Lovibond, 1995) was used to evaluate depression, anxiety, and stress levels via self-report. Likewise, state affect was measured via self-report using the Positive and Negative Affect Schedule (PANAS; Watson, Clark, \& Tellegen, 1988). A final self-report scale, the Behavioral Inhibition System/Behavioral Activation System Scale (BIS/BAS; Carver \& White, 1994), was administered to assess interindividual differences in motivational systems of approach and avoidance. Lastly, global cognitive function was assessed to identify dementia-related impairment using the MMSE (Folstein et al., 1975). Final sample characteristics are presented in Table 1. In addition to serving as filler tasks between the two experimental tasks, these background measures were included to control for any cognitive or affective differences in younger and older samples across 
Table 1

Group characteristics.

\begin{tabular}{|c|c|c|c|c|c|c|c|c|c|}
\hline & \multicolumn{4}{|c|}{ Younger Adults } & \multicolumn{4}{|c|}{ Older Adults } & \multirow{3}{*}{$\begin{array}{c}\text { Age effects } \\
F \text {-value }\end{array}$} \\
\hline & \multicolumn{2}{|c|}{ Control } & \multicolumn{2}{|c|}{ Motivated } & \multicolumn{2}{|c|}{ Control } & \multicolumn{2}{|c|}{ Motivated } & \\
\hline & $M$ & $S D$ & $M$ & $S D$ & $M$ & $S D$ & $M$ & $S D$ & \\
\hline $\mathrm{N}$ & 24 & - & 24 & - & 24 & - & 24 & - & - \\
\hline N (Female) & 16 & - & 16 & - & 16 & - & 16 & - & - \\
\hline Age, years & 25.00 & 4.82 & 23.04 & 4.38 & 67.42 & 6.34 & 67.50 & 6.76 & $1412.81 * * *$ \\
\hline Age range, years & $18-34$ & - & $18-33$ & - & $60-85$ & - & $61-87$ & - & - \\
\hline Education, years & 15.88 & 2.23 & 15.67 & 2.10 & 16.58 & 2.15 & 16.46 & 2.30 & 2.80 \\
\hline MHV & 18.08 & 3.05 & 17.17 & 3.57 & 22.04 & 4.67 & 22.83 & 4.04 & $36.96 * * *$ \\
\hline \multicolumn{10}{|l|}{ Digit symbol } \\
\hline Correct & 92.04 & 17.92 & 83.50 & 20.18 & 62.83 & 12.31 & 67.29 & 13.21 & $46.95^{* * *}$ \\
\hline Incorrect & 0.71 & 1.30 & 0.46 & 0.93 & 0.83 & 1.46 & 0.38 & 0.77 & .088 \\
\hline \multicolumn{10}{|l|}{ Digit span } \\
\hline Forward & 10.21 & 2.43 & 11.00 & 2.30 & 10.17 & 2.44 & 10.08 & 2.28 & .98 \\
\hline Backward & 7.38 & 2.18 & 6.67 & 2.08 & 6.58 & 2.12 & 6.13 & 1.73 & 2.57 \\
\hline MMSE & 29.42 & 0.83 & 29.54 & 0.66 & 29.17 & 0.92 & 29.08 & 0.97 & $4.14 *$ \\
\hline BIS & 21.71 & 4.29 & 21.04 & 4.39 & 18.75 & 3.71 & 18.75 & 2.79 & $11.18 * *$ \\
\hline Drive & 12.00 & 2.55 & 11.00 & 2.87 & 10.50 & 2.09 & 10.71 & 2.60 & 2.98 \\
\hline Fun seek. & 12.00 & 2.17 & 12.54 & 2.57 & 10.67 & 2.43 & 11.04 & 2.61 & $8.02 * *$ \\
\hline Reward Resp. & 17.83 & 2.22 & 17.46 & 1.69 & 16.25 & 2.21 & 17.42 & 2.28 & 3.54 \\
\hline BAS Total & 41.83 & 5.73 & 41.00 & 5.33 & 37.42 & 5.27 & 39.17 & 6.34 & - \\
\hline \multicolumn{10}{|l|}{ PANAS } \\
\hline Positive Aff & 30.29 & 10.32 & 32.54 & 10.50 & 35.56 & 6.03 & 38.58 & 6.38 & $10.45 * *$ \\
\hline Negative Aff & 11.63 & 2.14 & 12.83 & 3.13 & 11.13 & 1.54 & 10.54 & 1.10 & $10.40 * *$ \\
\hline \multicolumn{10}{|l|}{$D A S S-21$} \\
\hline Depression & 3.42 & 3.26 & 6.25 & 6.25 & 5.58 & 8.42 & 3.00 & 3.23 & .22 \\
\hline Anxiety & 3.33 & 3.94 & 7.08 & 6.75 & 3.75 & 4.18 & 2.67 & 3.16 & $4.34 *$ \\
\hline Stress & 8.17 & 8.25 & 13.25 & 9.90 & 8.33 & 7.09 & 8.08 & 5.39 & 2.44 \\
\hline
\end{tabular}

Note. MHV = Mill Hill Vocabulary Scale; MMSE = Mini Mental State Exam; BIS = Behavioural Inhibition System; BAS = Behavioural Approach System; PANAS = Positive Negative Affective Schedule; DASS-21 = Depression, Anxiety, and Stress Scale.

$* \mathrm{p}<.05 . * * \mathrm{p}<.01 . * * * \mathrm{p}<.001 ; F(1,92), 2$ (age: younger, older) by 2 (condition: control, motivated) between-subjects ANOVA 
the different conditions.

Materials. In both conditions, participants completed two computer-based tasks (described below) in which they viewed a series of face-name pairings on the screen. The face and name stimuli were selected as follows: using Minear and Park's (2004) grayscale face database (see Figure 1), 96 different neutral faces (48 younger, 24 female; 48 older, 24 female) were randomly chosen. Stimuli from this database have been empirically validated for perceived age, facial expression, familiarity, memorability and picture quality (K. M. Kennedy, Hope, \& Raz, 2009). Faces represented a diverse range of ethnicities.

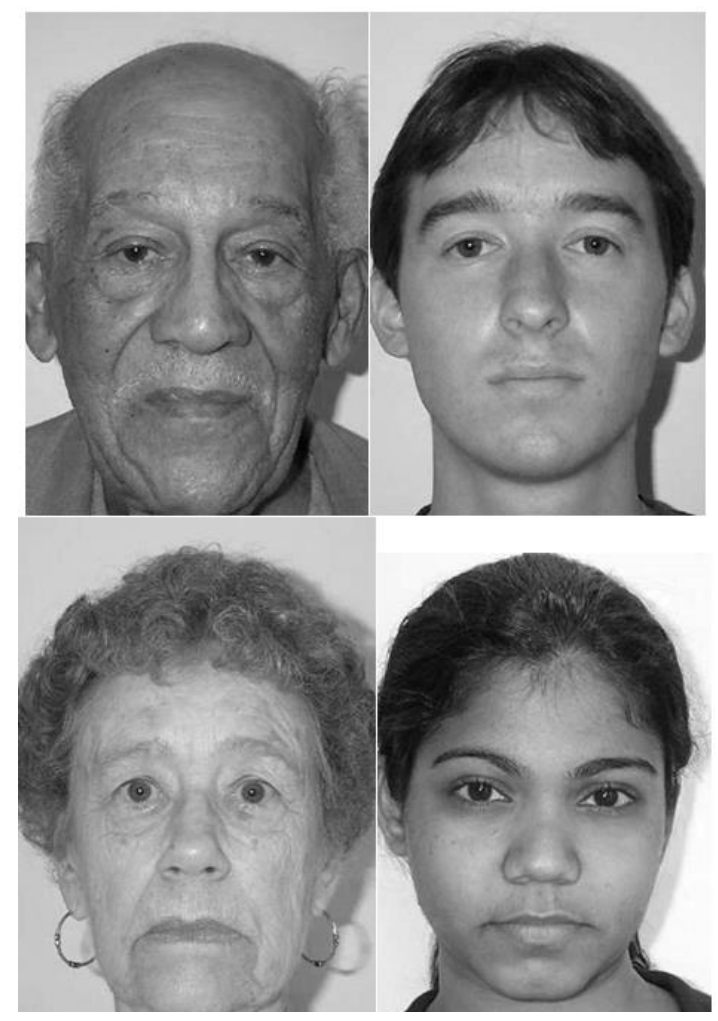

Figure 1. Face stimuli samples from Kennedy et al.'s (2009) normed database, originally derived from Minear \& Park (2005). Top row: old and young males, from left to right. Bottom row: old and young females, from left to right.

Considering same-age bias (Rhodes \& Anastasi, 2012) has been associated with performance at ceiling on the 1-back task used (Weeks et al., 2016), younger participants completed the tasks with older faces and older participants with younger faces; this was expected to lead to greater task difficulty (and thus higher engagement) and more variability in 
performance as demonstrated in Weeks et al.'s (2016) third experiment. Likewise, 96 names were selected from Service Ontario's top 50-100 baby names

(https://www.ontario.ca/data/ontario-top-baby-names) in the same age and sex proportions used for face selection. Face-name pairs were constructed such that names appeared across the faces' foreheads. Faces were presented centrally on a white screen, with the capitalized names written in red, size 36, Arial font. Face-name pairings, as well as the assignment of critical versus filler pairs (described below), were randomly selected by E-prime presentation software for each participant.

The 1-back task was administered via E-prime presentation software and included 4 blocks comprising 144 trials total, with 36 trials per block and a target trial occurring every six trials on average. Each trial, or face presentation, lasted 1000 milliseconds and the inter-stimulus interval was 500 milliseconds. There were 16 critical face-name pairs among 144 trials, which were shown three times each in their respective block. In other words, 48 of 144 trials involved a critical pair. The remaining 96 trials consisted of filler faces and names, which were either nback targets or regular filler trials. Of the 16 critical pairs, eight were "maintained" and eight were "re-arranged" in the subsequent study phase. In both conditions, each critical pair was assigned to a single block, with four different critical pairs per block (2 maintained and 2 rearranged per block). For condition 2, this meant that each critical pair was only encountered in one motivational condition (i.e., high or low). As such, eight pairs (4 maintained, 4 re-arranged) were confined to high-gain and eight (4 maintained, 4 re-arranged) to low-gain blocks with an equal distribution of maintained and re-arranged across the four blocks. To minimize the salience of these repeating critical pairs, all other filler face stimuli (which were not included in the study 
phase) were also repeated three times within their respective block. However, repeating filler face stimuli were always paired with different names.

In the control condition, blocks began with screens that labelled the "round" number. These served as placeholders for value cue screens that preceded blocks in the motivated condition. Value cues were introduced in the motivated condition to evoke sustained motivational states while the participants perform the 1-back task, with the expectation that higher motivation would be associated with high-gain over low-gain block types. High-gain $(+100,200$, or 300 points) blocks were contrasted with low-gain blocks during which only 1,2 or 3 virtual point(s) were at stake per correct response; the low-gain blocks were intended to act as a within-subjects control (low motivation) akin to the 1-back task used in the control condition (which acted as a between-subjects control for the motivation manipulation; no motivation).

Blocks ended with a screen that indicated the end of the "round" in the control condition, and with feedback screens indicating points earned in the motivated condition. Additionally, as a manipulation check in the motivated condition, self-reported ratings of valence and arousal were elicited after each block using valence and arousal rows of the Self-Assessment Manikins (SAM; Bradley \& Lang, 1994; Spaniol, Voss, \& Grady, 2008b) and a corresponding 5-point scale (see Figure 2).

Procedure. After providing consent, participants performed a shortened practice block of the task, consisting of 8 trials; faces were presented without distractor names and participants were instructed to press the spacebar when they saw the same face repeat for two consecutive trials. After these trials, participants were provided with rest of the instructions. They were told that names would be presented with the faces to make the task more difficult, but they should try to ignore them and only pay attention to the faces. Participants then completed two additional 


\section{How excited were you about your point earnings this round? Press a number from 1 to 5}

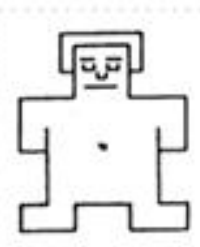

1

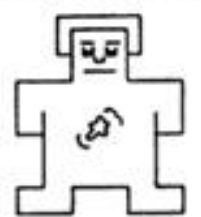

2

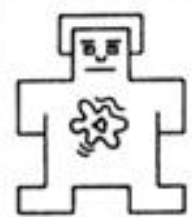

3

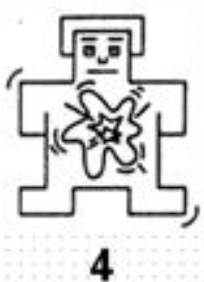

4

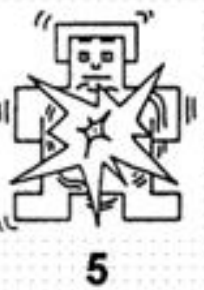

A)

\section{How positive is your mood right now? Press a number from 1 to 5}

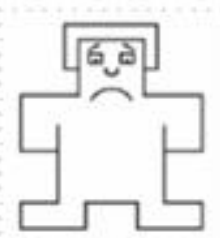

1

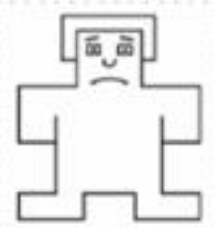

2

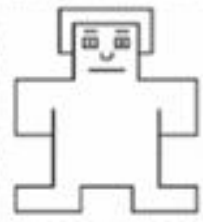

3

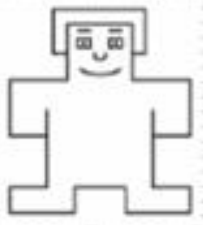

4

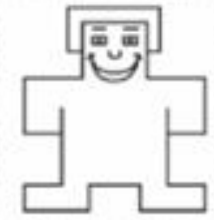

5

Figure 2. Post-feedback arousal and valence ratings. Participants responded with a number from 1 to 5 corresponding to least-to-most arousal/valence. A) 5-point Likert scale for the post-feedback arousal rating, collected after each block. B) A) 5-point Likert scale for the post-feedback valence rating, collected after each block.

shortened practice blocks (each 24 trials long) in which names were super-imposed on the faces.

In the motivated condition, the practice blocks introduced the value manipulation, allowing participants to practice both a high- and a low-gain round. Faces and names used in practice trials were not included in the actual task. Afterward, participants began the experimental 1-back task in which face stimuli were randomly paired with distractor names. Again, they were 
instructed to press the spacebar when the same two faces appear in succession and to ignore the names superimposed on the foreheads of the faces.

In the control condition, each block began with an introduction screen showing the "round" number, followed by a fixation cross, followed by the 36 trials, and terminated with a screen that indicated the end of the block. Another fixation cross followed before the onset of the subsequent "round". On average, a target trial (repeated face) occurred every six trials, and the target never included a critical face-name pair (one that would be used in the subsequent memory test). See Figure 3A for a depiction of the control 1-back task. The design was identical for the motivated condition, but here the 1-back task was divided into four value-cued blocks, with 36 trials (face presentations) per block. Similarly, each block began with a value cue screen, followed by a fixation cross, followed by the 36 trials, followed by a screen that provided block feedback, and ended with an arousal and a valence rating screen. Another fixation cross appeared before the onset of the subsequent block. Value-cues indicated whether the block was a highgain round (i.e., potential for 100, 200, or 300 points per correct response) or a low-gain round (i.e., potential for only 1, 2, or 3 point(s) per correct response). To maintain the attention of the participant and create uncertainty, reward was given with a probability of $60 \%$ (Gruber, Ritchey, Wang, Doss, \& Ranganath, 2016; Mason, Farrell, Howard-Jones, \& Ludwig, 2017) for every correct response made within a 1 second trial. Block feedback informed participants of their earnings from that round. Alternatingly, each participant performed two of each block type for a total of four blocks, and block type order was counter-balanced across participants within each age-group and across gender. See Figure 3B \& 3C for a depiction of the different value-cued 1back task blocks. In both conditions, a correct response encompassed both responding when a face repeated, as well as not responding when a face did not repeat. 


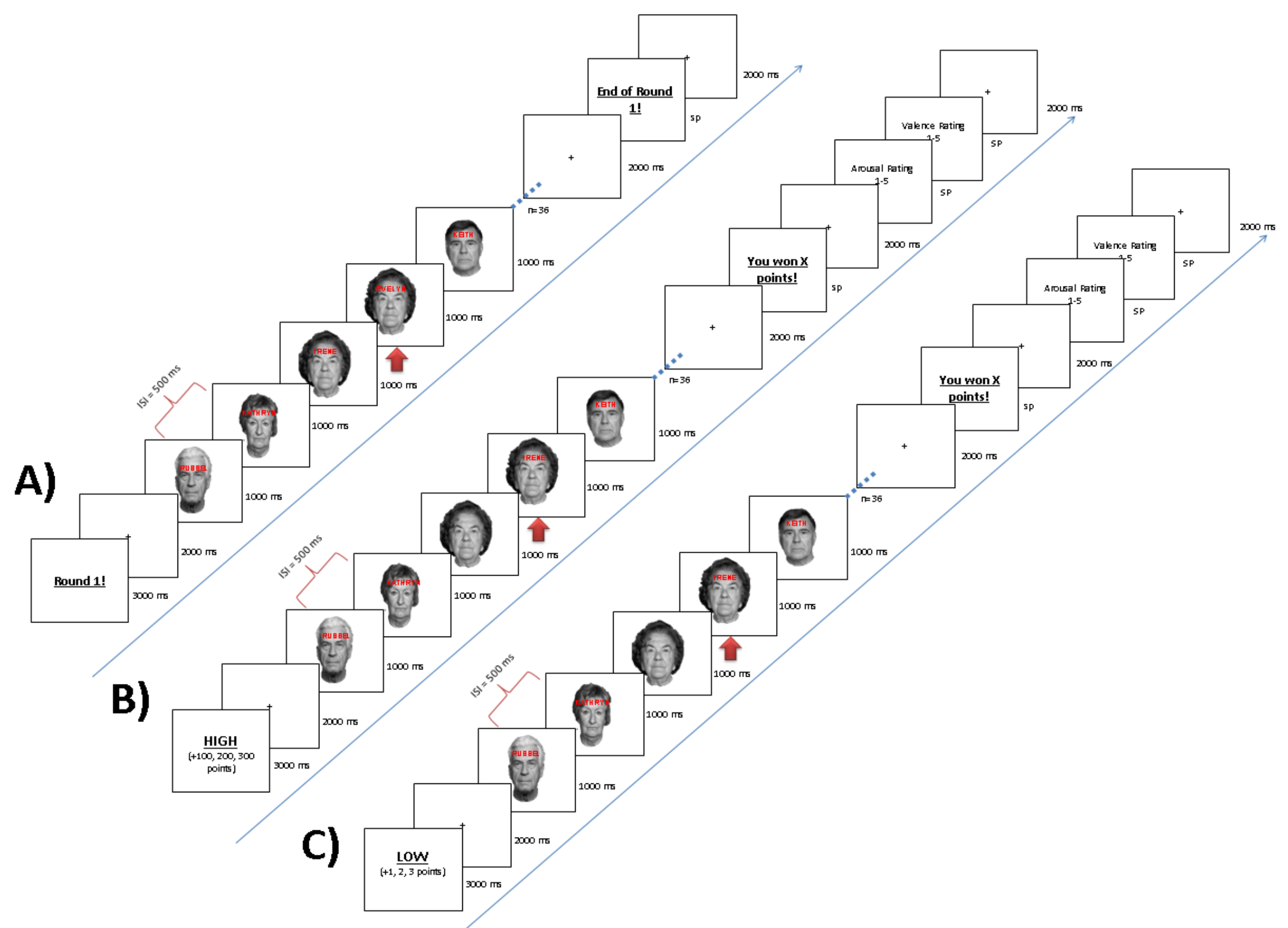

Figure 3. Schematic of the different types of 1-back tasks viewed by younger adults (old faces). A) The control 1-back task employed in the control condition. B) High-gain 1-back block from the motivated condition. C) Low-gain 1-back block from the motivated condition. The red arrows indicate target trials. The face stimuli are to-be attended and superimposed names to-be ignored. Older adults viewed young faces; sp: self-paced 
After this task and before the onset of the second phase, participants completed a variety of background measures to assess cognitive ability, affect, and disposition (as detailed above, under Background Measures). This occurred over a 20-minute interval.

Participants then began the study phase of the experiment, during which they studied 16 face-name pairs presented in an identical fashion to the 1-back task without the initial and final screens. However, during study, pairs were presented for 4 seconds each. Importantly, half of the pairs were maintained (i.e., seen together during the 1-back task) and half were re-arranged (i.e., seen separately during the 1-back task). In the motivated condition, half of each pair type (maintained and re-arranged) originated from high-gain blocks, with the other half originating from low-gain blocks.

After study, memory for the face-name pairings was tested by prompting the participants with a picture of the face in a different order than during the study phase. Participants were asked to respond out loud with the corresponding name and the researcher recorded each response and whether the response was accurate. As in the study phase, faces were presented at rate of 4 seconds.

Lastly, participants completed an open-ended awareness questionnaire (Adapted from Campbell et al., 2010; see Appendix I) delivered in the style of an interview to ensure they did not identify the connection between the 1-back task and the memory tasks. Responses to the interview items were recorded by the researcher. In the motivated condition, as a final manipulation check for the motivating effect of the virtual points, the awareness interview began by asking whether or not participants were motivated by the points and - if they were-whether they felt more motivated during high- versus low-gain rounds (see Appendix I). After the awareness interview, participants were debriefed and compensated. 


\subsection{Results}

Background Measures. To assess potential age differences and condition differences in background measures, each of the seven measures were analyzed using a 2 (age: younger, older) x 2 (condition: control, motivated) between-subjects design. Age effects are summarized in Table 1.

MHV. There was a main effect of age on MHV performance. Across conditions, older adults $(M=22.44, S D=4.34)$ scored higher than younger adults $(M=17.63, S D=3.32)$ on the vocabulary scale, $F(1,92)=36.96, p<.01, \eta_{p}{ }^{2}=.29$. There was no main effect of condition or any significant interaction between age and condition $(p=.94, p=.24$, respectively).

Digit Symbol Substitution. There was a main effect of age only for correct responses on the digit symbol substitution task. Compared to older adults $(M=65.06, S D=12.83)$, younger adults $(M=87.77, S D=19.37)$ gave significantly more correct responses on the task, $F(1,92)=$ $46.95, p<.01, \eta_{p}{ }^{2}=.39$, but there was no significant age difference in the number of incorrect responses $(p=.93)$. Moreover, there was no main effect of condition (correct: $p=.54$; incorrect: $p=.14$ ) or any significant Age $\mathrm{x}$ Condition interactions (correct: $p=.05$; incorrect: $p=.66$ ).

Digit Span. There were no significant age differences in performance on the forward ( $p=$ .32) or backward $(p=.11)$ digit span task. Likewise, there were no significant condition differences in the forward $(p=.47)$ or backward $(p=.16)$ digit span performance. The Age $\mathrm{x}$ Condition interactions were not significant (forward: $p=.37$; backward: $p=.76$ ).

MMSE. There was a main effect of age on MMSE scores. On average, younger adults ( $M$ $=29.48, S D=.74)$ scored slightly higher than older adults $(M=29.13, S D=.94)$ on the MMSE. This marginal difference was significant, $F(1,92)=4.14, p=.04, \eta_{p}^{2}=.043$. There was no main effect of condition $(p=.91)$ and the Age $\mathrm{x}$ Condition interaction was not significant $(p=.55)$. 
$\boldsymbol{B I S / B A S}$. Items on the BIS/BAS pertain to either the behavioural inhibition scale (BIS) or behavioural activation scale (BAS) which consists of three subscales (Fun-seeking, Reward responsiveness and Drive).

$B I S$. There was a main effect of age on BIS scores. Younger adults $(M=21.38, S D=$ 4.31) scored higher than older adults $(M=18.75, S D=3.25), F(1,92)=11.180, p<.01, \eta_{p}{ }^{2}=$ .11. There was no main effect of condition $(p=.67)$ and the Age $\mathrm{x}$ Condition interaction was not significant $(p=.67)$.

$B A S$. While items related to reward responsiveness and drive showed no significant age differences ( $p=.07$ and $p=.09$, respectively), there was a main effect of age on items related to the fun-seeking sub-scale. Younger adults $(M=12.27, S D=2.37)$ scored significantly higher than older adults $(M=10.85, S D=2.50)$ on this sub-scale, $F(1,92)=8.02, p<.01, \eta_{p}{ }^{2}=.08$. There was no main effect of condition on any of the BAS component scales (reward: $p=.36$; drive: $p=.45$; fun: $p=.36$ ), nor any significant Age $\mathrm{x}$ Condition interactions (reward: $p=.08$; drive: $p=.25$; fun: $p=.87$ ).

PANAS. The PANAS contains items that pertain to either positive affect or negative affect sub-scales. There was a main effect of age on both positive and negative affect scores. On average, older adults identified with more positive affective words $(M=37.07, S D=6.33)$ than younger adults $(M=31.42, S D=10.36), F(1,92)=10.45 p<.01, \eta_{p}{ }^{2}=.10$. Similarly, younger adults identified with more negative affective words $(M=12.23, S D=2.72)$ than older adults $(M$ $=10.83, S D=1.36), F(1,92)=10.40, p<.01, \eta_{p}{ }^{2}=.10$. While there was no main effect of condition on either sub-scale, the main effect of age on negative affect scores was qualified by a significant Age $\mathrm{x}$ Condition interaction, $F(1,92)=19.26, p=.04, \eta_{p}{ }^{2}=.05$. Simple effects revealed that for the control group, there was no significant difference between older and 
younger adults' negative affective word scores $(p=.42)$. However, In the motivated condition, younger adults $(M=12.83, S D=3.13)$ scored significantly higher than older adults $(M=10.54$, $S D=1.10)$ on the negative affective sub-scale, $F(1,92)=14.02, p<.01, \eta_{p}{ }^{2}=.13$. There was no significant Age $\mathrm{x}$ Condition interactions for the positive sub-scale $(p=.83)$.

DASS-21. The DASS-21 includes three sub-scales: depression, anxiety and stress. There was only a main effect of age for the anxiety sub-scale. That is, older and younger adults did not different significantly on scores for self-reported depression or stress $(p=.65$ and $p=.13$, respectively). However, younger adults $(M=5.21, S D=5.79)$ reported significantly higher levels of anxiety than older adults $(M=3.21, S D=3.71), F(1,92)=4.34, p=.04, \eta_{p}{ }^{2}=.05$. There was no main effect of condition on any of the three sub-scales (depression: $p=.92$; anxiety: $p=.17$; stress: $p=.13$ ). However, the main effect of age on anxiety was qualified by a significant Age x Condition interaction, $F(1,92)=6.33, p=.01, \eta_{p}{ }^{2}=.06$. Simple effects revealed that for the control group, there was no significant difference between older and younger adults' anxiety score $(p=.76)$. However, In the motivated condition, younger adults ( $M$ $=7.08, S D=6.75)$ scored significantly higher than older adults $(M=2.67, S D=3.16)$ on the anxiety sub-scale, $F(1,92)=10.57, p<.01, \eta_{p}^{2}=.10$.

Overall, older adults performed better on our measure of verbal intelligence and reported more positive state affect. Younger adults performed better on our measure of processing speed, global cognition, scored higher on avoidance-related motivation, scored higher on motivation related to fun-seeking, reported more negative state affect, and reported higher anxiety. Interestingly, the higher levels of negative state affect and anxiety in younger adult participants were specific to the motivated condition with no age difference in these measures in the control condition. Background measures with age differences and/or condition differences were included 
in subsequent analyses as covariates. However, results of these analyses were not different with the addition of the covariates and therefore, results are reported without the covariates.

Replication: Control performance. To address our replication hypothesis, data from the 1-back task and memory test for control condition participants were analyzed.

1-back performance. Potential age differences in 1-back performance (i.e., accuracy and reaction time) in the control condition were assessed using independent samples t-tests. For accuracy, equal variances were not assumed. As reported by Weeks et al. (2016) in their third experiment, there was no significant age difference in 1-back accuracy in the control condition $(p$ $=.11)$. Consistent with Campbell et al. $(2010)$, younger adults $(M=541.70, S D=89.42)$ were significantly faster to respond to 1 -back targets than older adults $(M=603.53, S D=71.98) ; t(46)$ $=-2.64, p .=.01$.

Overall, younger adults were found to be faster than older adults, which replicated findings from the original hyper-binding study conducted by Campbell et al. (2010). In line with Weeks et al. (2016), younger adults and older adults were matched in accuracy on the 1-back task.

Recall performance. Recall for names was analyzed using a 2 (age: younger, older) x 2 (pair type: maintained, re-arranged) mixed ANOVA with repeated measures on the second factor. The ANOVA revealed a main effect of pair type, $F(1,46)=6.51, p<.01, \eta_{p}{ }^{2}=.17$, which was qualified by a significant Age $\mathrm{x}$ Pair Type interaction, $F(1,46)=20.04, p<.01, \eta_{p}{ }^{2}=.30$. An analysis of simple effects revealed that older adults remembered significantly more names from maintained $(M=3.29, S D=.34)$ pairs than from re-arranged $(M=2.00, S D=.34)$ pairs, $F(1,46)=28.14, p<.01, \eta_{p}{ }^{2}=.38$. For younger adults, recall was not significantly different 
between the two pair types ( $p=.31)$. Unlike in the study by Weeks et al. (2016), there was no significant main effect of age $(p=.29)$.

To summarize, we replicated the Age x Pair Type interaction reported by Weeks et al. (2016), indicative of the age-related hyper-binding effect. However, contrary to Weeks et al. (2016), older and younger adults were found to recall a similar number of names on average.

Motivation \& Hyperbinding: Control vs. motivated performance. To investigate the effect of motivational incentives on 1-back performance and hyper-binding, data were analyzed for both control and motivated condition participants as well as within the motivated condition alone.

Hypothesis 1: Point manipulation. The first set of analyses assessed the effect of motivation, induced by the point manipulation, on 1-back performance and the hyper-binding effect.

1-back performance. Reaction time and accuracy on the 1-back task were each assessed using a 2 (age: younger, older) x 2 (condition: control, motivated) between-subjects design. See Table 2 for a summary of results.

Table 2

1-back performance as a function of age group and experimental condition

\begin{tabular}{|c|c|c|c|c|c|c|c|c|}
\hline & \multicolumn{4}{|c|}{ Younger Adults } & \multicolumn{4}{|c|}{ Older Adults } \\
\hline & \multicolumn{2}{|c|}{$\begin{array}{c}\text { Condition } 1 \\
\text { (control) }\end{array}$} & \multicolumn{2}{|c|}{$\begin{array}{r}\text { Condition } 2 \\
\text { (motivated) }\end{array}$} & \multicolumn{2}{|c|}{$\begin{array}{c}\text { Condition } 1 \\
\text { (control) }\end{array}$} & \multicolumn{2}{|c|}{$\begin{array}{l}\text { Condition } 2 \\
\text { (motivated) }\end{array}$} \\
\hline & $M$ & $S D$ & $M$ & $S D$ & $M$ & $S D$ & $M$ & $S D$ \\
\hline 1-back RT & 541.70 & 89.42 & 525.66 & 56.52 & 603.53 & 71.98 & 589.63 & 104.20 \\
\hline 1-back Acc & 0.93 & 0.07 & 0.93 & 0.08 & 0.88 & 0.13 & 0.90 & 0.08 \\
\hline
\end{tabular}

For reaction time, the ANOVA revealed a main effect of age, $F(1,92)=13.95, p<.01, \eta_{p}{ }^{2}$ $=.13$ (see Figure 4a). Across conditions, younger adults $(M=533.67, S D=74.44)$ were faster 
to respond to 1 -back target trials than older adults $(M=596.58, S D=88.87)$. There was no main effect of condition $(p=.44)$, and the Age $\mathrm{x}$ Condition interaction was not significant $(p=.87)$. Likewise, for accuracy, the ANOVA revealed a main effect of age, $F(1,91)=4.37, p=.04, \eta_{p}{ }^{2}=$ .05 (see Figure $4 \mathrm{~b})$. Across conditions, younger adults $(M=.93, S D=.07)$ were more accurate than older adults $(M=.89, S D=.12)$ at identifying 1-back targets. Again, there was no main effect of condition $(p=.59)$ and the Age x Condition interaction was not significant $(p=.51)$.

A)

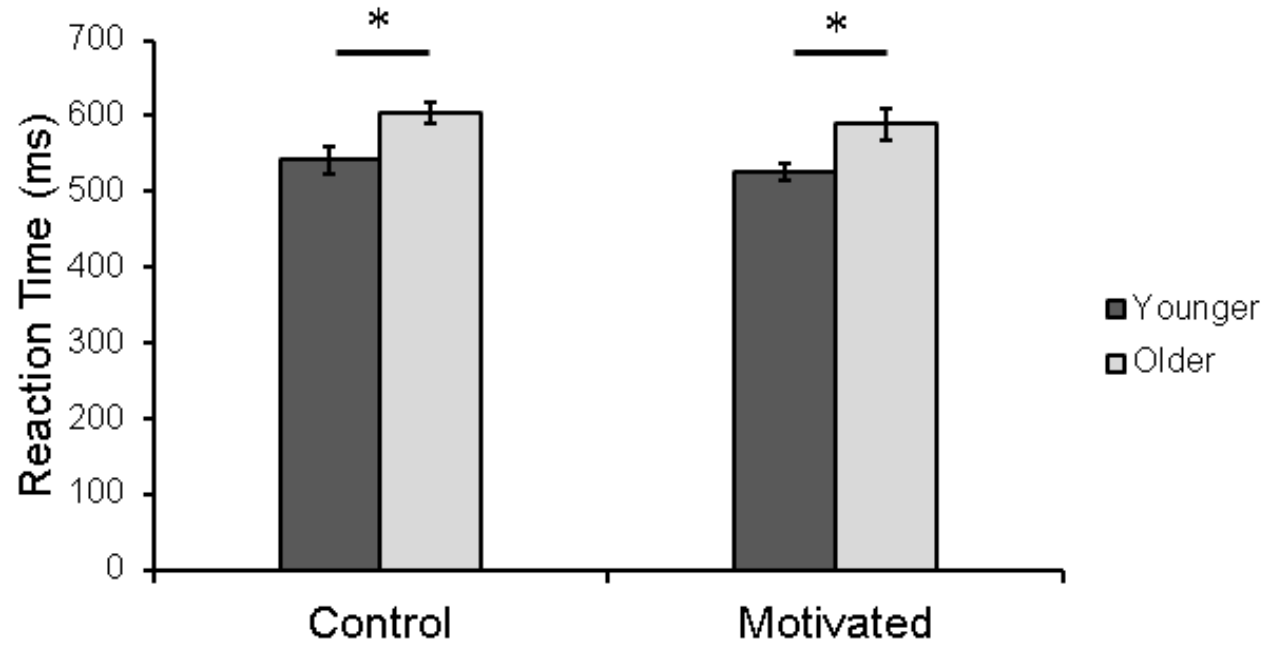

B)

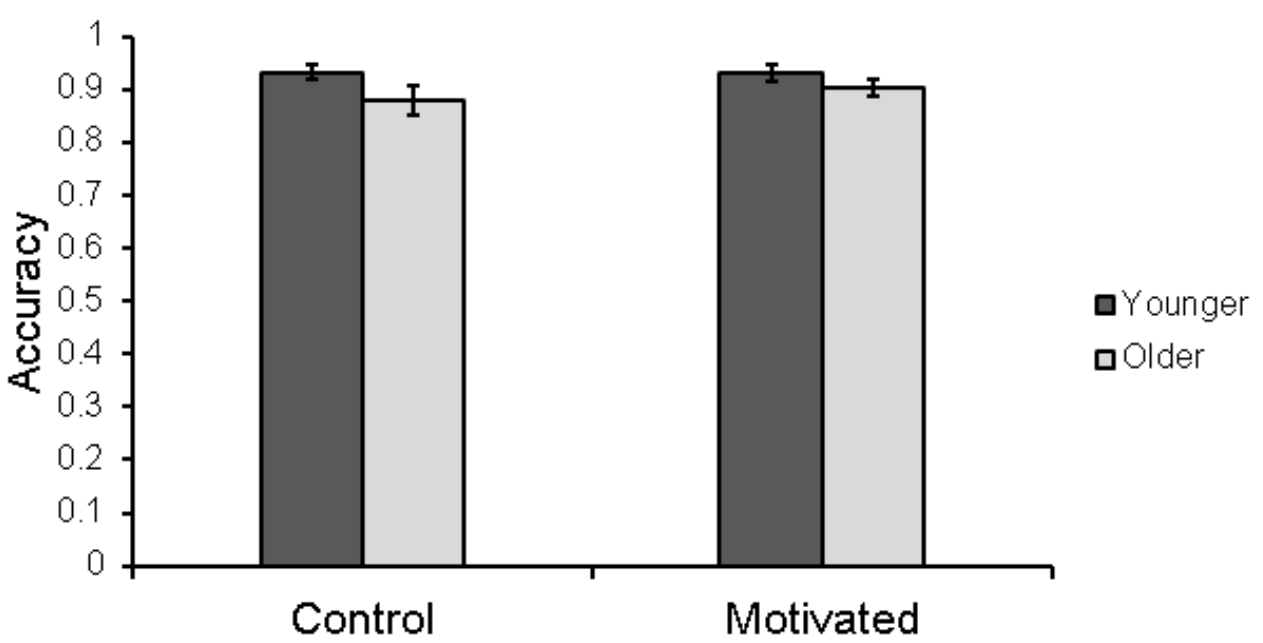

Figure 4. A) Reaction times in ms for younger (dark) and older (light) adults during the 1-back task in the control and motivated conditions. B) Accuracy (calculated as n-back target hit rate minus false alarm rate) for younger and older adults during control and motivated versions of the the 1-back task. *significant at the .05 level. 
Recall performance. Recall for names was analyzed using a 2 (age: younger, older) x 2 (condition: control, motivated) x 2 (pair type: maintained, re-arranged) mixed design, with repeated measures on the last factor. Summary statistics are reported in Table 3.

Table 3

Recall performance as a function of age group and experimental condition

\begin{tabular}{|c|c|c|c|c|c|c|c|c|}
\hline & \multicolumn{4}{|c|}{ Condition 1 (control) } & \multicolumn{4}{|c|}{ Condition 2 (motivated) } \\
\hline & \multicolumn{2}{|c|}{ Maintained } & \multicolumn{2}{|c|}{ Re-arranged } & \multicolumn{2}{|c|}{ Maintained } & \multicolumn{2}{|c|}{ Rearranged } \\
\hline & $M$ & $S D$ & $M$ & $S D$ & $M$ & $S D$ & $M$ & $S D$ \\
\hline Younger & & & & & & & & \\
\hline Adults & 3.00 & 1.62 & 3.25 & 1.85 & 3.29 & 2.10 & 2.83 & 1.69 \\
\hline Older & & & & & & & & \\
\hline Adults & 3.29 & 1.73 & 2.00 & 1.41 & 2.08 & 1.47 & 2.13 & 1.60 \\
\hline
\end{tabular}

The ANOVA revealed that main effects of age, $F(1,92)=5.16, p=.03, \eta_{p}{ }^{2}=.05$, and pair type, $F(1,92)=6.81, p=.01, \eta_{p}{ }^{2}=.07$, were qualified by an Age $\mathrm{x}$ Condition $\mathrm{x}$ Pair Type interaction, $F(1,92)=13.35, p<.01, \eta_{p}{ }^{2}=.13$ (see Figure 5). On average, younger adults $(M=$ 6.17, $S D=3.35)$ remembered significantly more names than older adults $(M=4.77, S D=2.78)$, $F(1,92)=5.16, p=.03, \eta_{p}{ }^{2}=.05$. Simple effects revealed that for older adults, recall for names originating from maintained pairs was significantly higher than recall for names originating from re-arranged pairs in the control condition, $F(1,92)=21.37, p<.01, \eta_{p}{ }^{2}=.19$. However, for the motivated condition, older adults' recall was not significantly different across pair type, $p=.88$. Moreover, younger adults' recall was not significantly different across pair type for both the control condition, $p=.37$, and the motivated condition, $p=.10$.

In sum, the point manipulation was associated with a similar pattern in 1-back performance to the control condition, however here younger adults were also more accurate. As reported by Weeks et al. (2016), younger adults recalled more names overall. Unlike the control 
condition, the age-related hyper-binding effect was not present in the motivated condition where older adults no longer showed a recall advantage for maintained over re-arranged pair names.

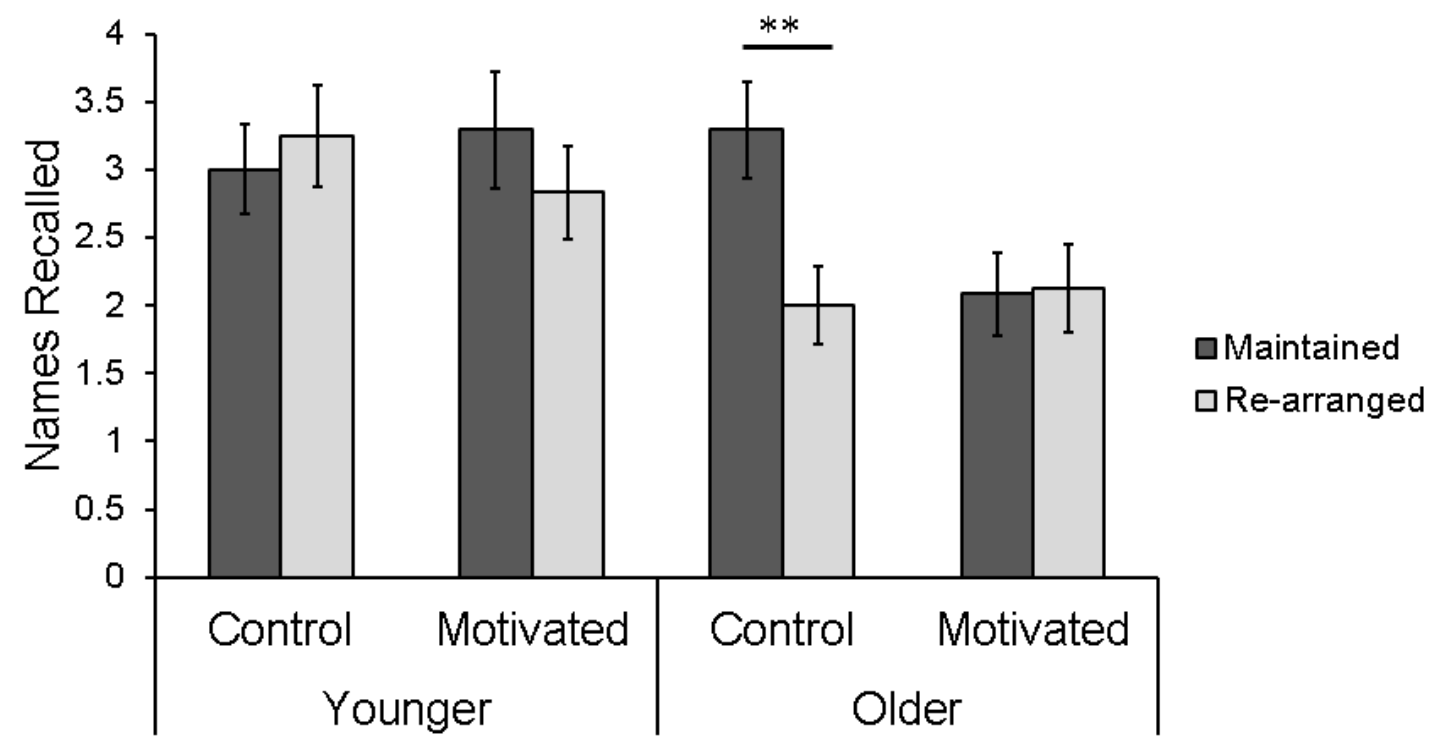

Figure 5. Recall for younger (left) and older (right) adults for names originating from maintained (dark) and rearranged (light) pairs, across control and motivated conditions. **significant at the .01 level.

In sum, the point manipulation was associated with a similar pattern in 1-back performance to the control condition, however here younger adults were also more accurate. As reported by Weeks et al. (2016), younger adults recalled more names overall. Unlike the control condition, the age-related hyper-binding effect was not present in the motivated condition where older adults no longer showed a recall advantage for maintained over re-arranged pair names.

Hypothesis 2: Value manipulation. The second phase of analyses focused on the effect of the value manipulation within the motivated condition.

Arousal and valence. As a check for the motivating quality of the value manipulation, arousal ratings were assessed using a 2 (age: younger, older) x 2 (block: low, high) mixed design with repeated measures on the second factor. See Table 4 for a summary of results. 
Table 4

Arousal and valence ratings as a function of age group and incentive level in the motivated condition

\begin{tabular}{|c|c|c|c|c|c|c|c|c|}
\hline & \multicolumn{4}{|c|}{ Arousal } & \multicolumn{4}{|c|}{ Valence } \\
\hline & \multicolumn{2}{|c|}{$\begin{array}{l}\text { Low-gain } \\
\text { (control) }\end{array}$} & \multicolumn{2}{|c|}{$\begin{array}{l}\text { High-gain } \\
\text { (motivated) }\end{array}$} & \multicolumn{2}{|c|}{$\begin{array}{c}\text { Low-gain } \\
\text { (control) }\end{array}$} & \multicolumn{2}{|c|}{$\begin{array}{l}\text { High-gain } \\
\text { (motivated) }\end{array}$} \\
\hline & $M$ & $S D$ & $M$ & $S D$ & $M$ & $S D$ & $M$ & $S D$ \\
\hline Younger & & & & & & & & \\
\hline Adults & 3.75 & 0.92 & 4.02 & 1.04 & 3.92 & 0.72 & 4.06 & 0.71 \\
\hline Older & & & & & & & & \\
\hline Adults & 3.81 & 0.95 & 3.96 & 1.02 & 4.35 & 0.68 & 4.44 & 0.66 \\
\hline
\end{tabular}

The ANOVA revealed a main effect of block type, $F(1,46)=7.53, p<.01, \eta_{p}{ }^{2}=.09$, which was not qualified by the higher order Age x Block interaction (see Figure 6). On average, participants rated high-gain block earnings $(M=3.99, S D=1.01)$ as more exciting than low-gain block earnings $(M=3.79, S D=.93)$ regardless of age group.

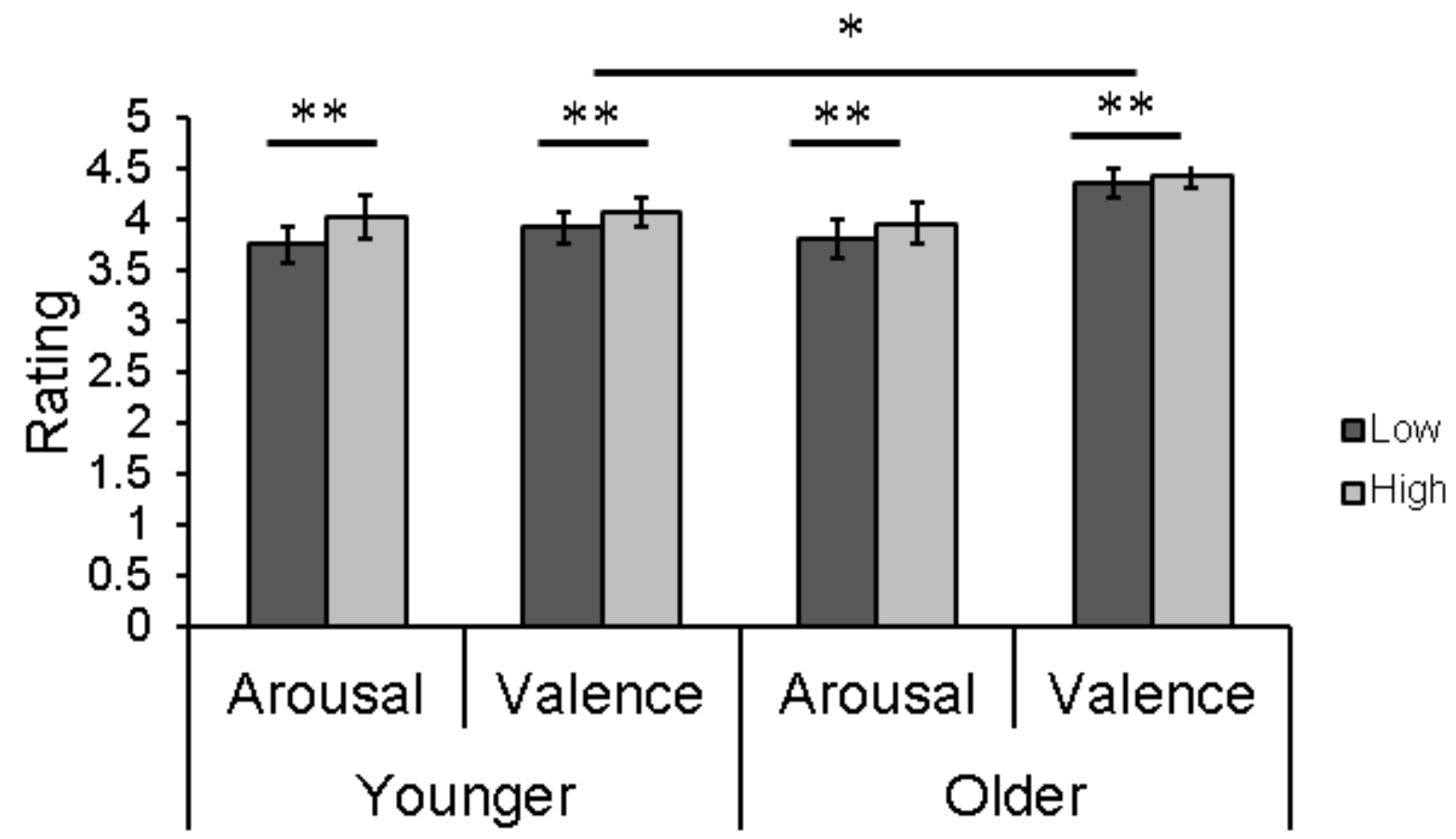

Figure 6. Ratings of arousal and valence from low-gain (dark) and high-gain (light) blocks for younger (left) and older (right) adults. Ratings were made using a 5-point Likert scale. *significant at the .05 level;

**significant at the .01 level 
To address the possibility of any confounding effect of affect, valence ratings were assessed using a 2 (age: younger, older) x 2 (block: low, high) mixed design with repeated measures on the second factor. Results are summarized above in Table 4. The ANOVA revealed a main effect of block, $F(1,46)=8.11, p<.01, \eta_{p}{ }^{2}=.09$, and age, $F(1,46)=4.28, p=.04, \eta_{p}{ }^{2}=.09$ (see Figure 6). The Age x Block interaction was not significant. On average, participants rated their moods as more positive following high-gain $(M=4.25, S D=.71)$ blocks compared to low-gain $(M=4.14, S D=.73)$ blocks. Moreover, regardless of block type, older adults $(M=4.40, S D=$ $.66)$ indicated more positive mood ratings than did younger adults $(M=3.99, S D=.70)$.

Therefore, both excitement and mood were modulated by block type across age groups, with higher incentive associated with more excitement and more positive mood. The moodboosting effect was more prominent in older adults than younger adults.

Motivation interview. Out of 48 participants, 29 reported feeling motivated by the points (60\%). Out of those participants, only 14 (48\%) reported feeling more motivated during highgain rounds than during low-gain rounds. Chi square tests were performed to examine the relation between age and interview responses. For question 1, the relationship was not significant $(p=.77)$. That is, a similar proportion of younger and older adults reported feeling motivated by the points. However, for question 2, the relationship was significant and more younger than older adults reported feeling a difference in motivation between high- and low-gain rounds, $X^{2}(1, N=$ 48) $=10.54, p<.01$.

1-back performance. Reaction time and accuracy were each assessed using a 2 (age: younger, older) x 2 (block: low-gain, high-gain) mixed design with repeated measures on the last factor. See Table 5 for a summary of results. 
Table 5

1-back performance as a function of age group and incentive level in the motivated condition

\begin{tabular}{|c|c|c|c|c|c|c|c|c|}
\hline & \multicolumn{4}{|c|}{ Younger Adults } & \multicolumn{4}{|c|}{ Older Adults } \\
\hline & \multicolumn{2}{|c|}{$\begin{array}{l}\text { Low-gain } \\
\text { (control) }\end{array}$} & \multicolumn{2}{|c|}{$\begin{array}{c}\text { High-gain } \\
\text { (motivated) }\end{array}$} & \multicolumn{2}{|c|}{$\begin{array}{l}\text { Low-gain } \\
\text { (control) }\end{array}$} & \multicolumn{2}{|c|}{$\begin{array}{c}\text { High-gain } \\
\text { (motivated) }\end{array}$} \\
\hline & $M$ & $S D$ & $M$ & $S D$ & $M$ & $S D$ & $M$ & $S D$ \\
\hline 1-back RT & 520.69 & 55.83 & 531.34 & 72.83 & 591.30 & 99.85 & 588.16 & 111.70 \\
\hline 1-back Acc & 0.94 & 0.08 & 0.93 & 0.09 & 0.91 & 0.09 & 0.91 & 0.09 \\
\hline
\end{tabular}

For reaction time, the ANOVA revealed a main effect of age, $F(1,46)=1.13, p=.29, \eta_{p}{ }^{2}$ $=.02$. Regardless of block type, younger adults $(M=525.66, S D=56.52)$ were faster than older adults $(M=589.63, S D=104.20)$. There was no main effect of block and the Age $\mathrm{x}$ Block interaction was not significant. For accuracy, the ANOVA did not reveal any main effects or a significant interaction. For a depiction of reaction time and accuracy results, see Figures 7 a and $7 \mathrm{~b}$, respectively.

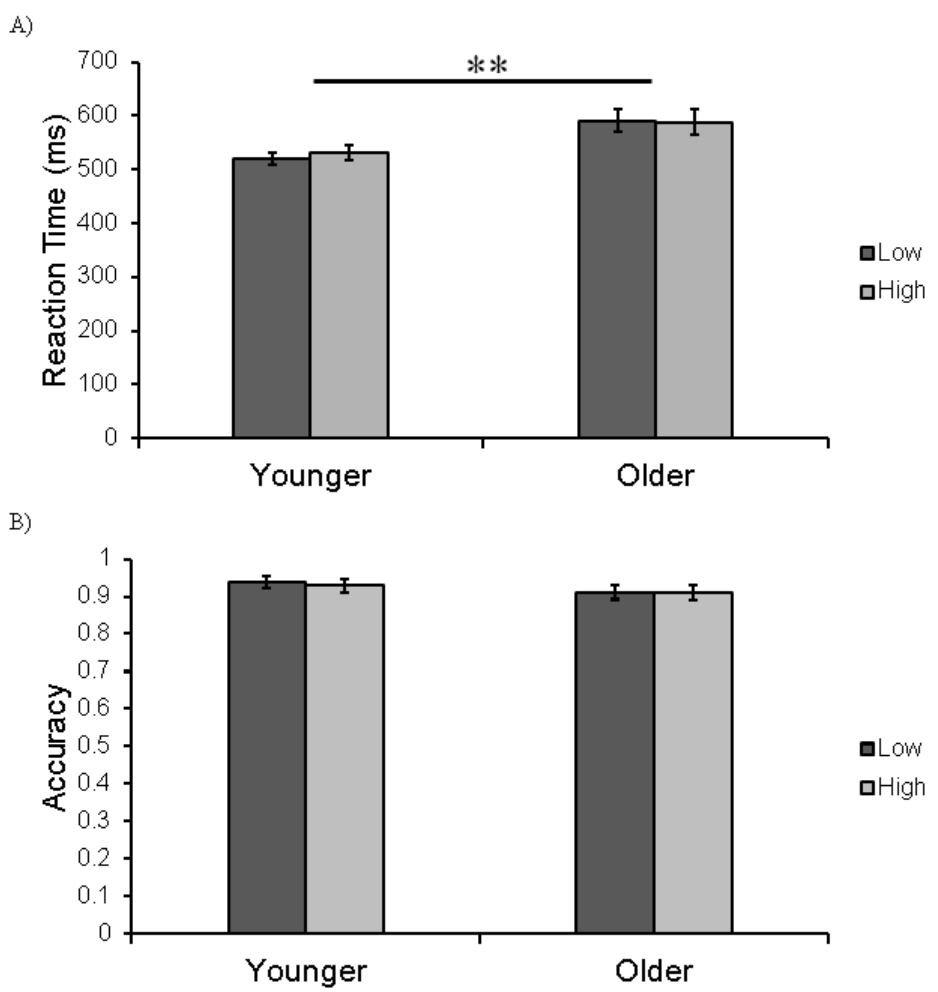

Figure 7. A) Reaction times in ms for younger (left) and older (right) adults during the 1-back task in the low-gain (dark) and high-gain (light) blocks. B) Accuracy (calculated as n-back target hits minus false alarms) for younger and older adults during the 1-back task on low-gain and high-gain blocks. **significant at the .01 level. 
Recall performance. To investigate whether the dampening effect of motivation on hyper-binding was modulated by point value, recall was assessed using a 2 (age: younger, older) x 2 (block: low, high) x 2 (pair type: maintained, re-arranged) mixed ANOVA with repeated measures on the last two factors. Summary statistics are reported in Table 6.

Table 6

Recall performance as a function of age group, pair type and incentive level in the motivated condition

\begin{tabular}{|c|c|c|c|c|c|c|c|c|}
\hline & \multicolumn{4}{|c|}{ Low-gain (control) } & \multicolumn{4}{|c|}{ High-gain (motivated) } \\
\hline & \multicolumn{2}{|c|}{ Maintained } & \multicolumn{2}{|c|}{ Re-arranged } & \multicolumn{2}{|c|}{ Maintained } & \multicolumn{2}{|c|}{ Rearranged } \\
\hline & $M$ & $S D$ & $M$ & $S D$ & $M$ & $S D$ & $M$ & $S D$ \\
\hline Younger Adults & 1.71 & 1.12 & 1.21 & 1.10 & 1.54 & 1.28 & 1.63 & 1.10 \\
\hline Older Adults & 1.21 & 1.02 & 1.04 & 0.91 & 0.88 & 0.95 & 1.08 & 1.06 \\
\hline
\end{tabular}

The ANOVA revealed a main effect of age, $F(1,46)=4.35, p=.04, \eta_{p}{ }^{2}=.09$, which was not qualified by any significant higher-order interactions (see Figure 8). That is, regardless of block or pair type, younger adults $(M=6.13, S D=3.51)$ recalled more names than older adults $(M=$ $4.21, S D=2.64)$.

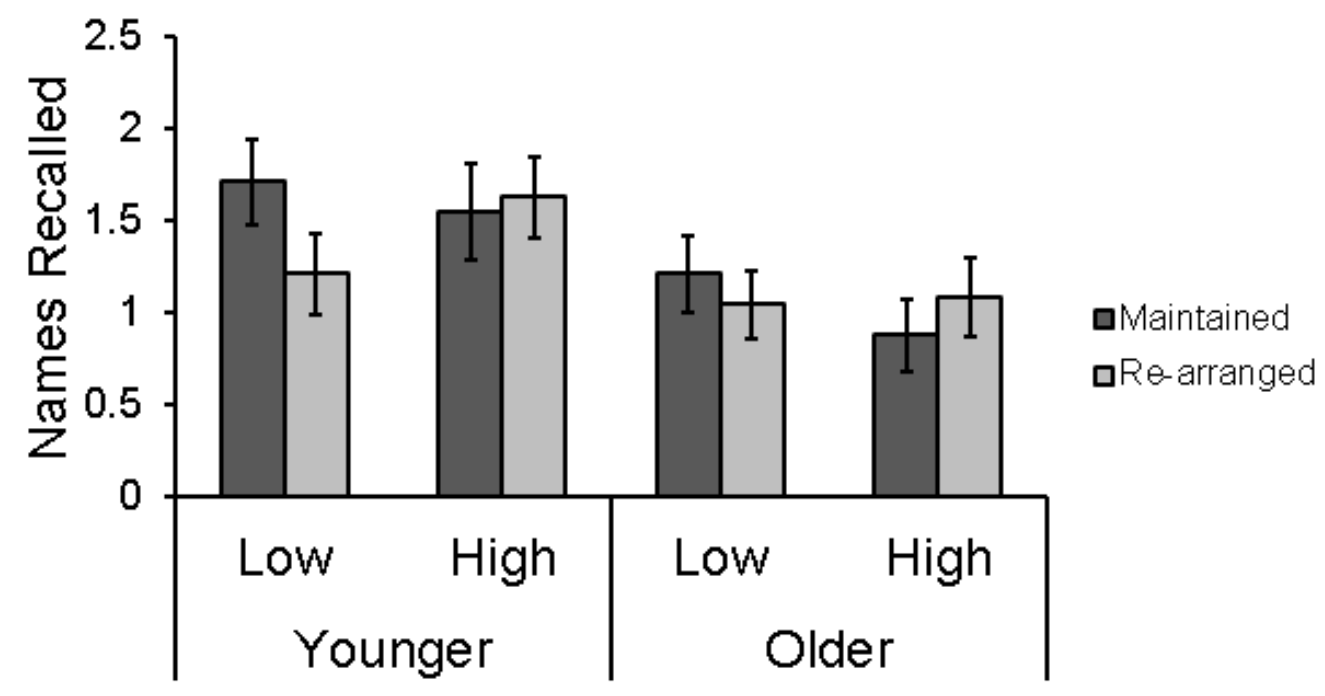

Figure 8. Recall for younger (left) and older (right) adults for names originating from maintained (dark) and rearranged (light) pairs, across low-gain (non-motivated) and high-gain (motivated) blocks. 
As in the control condition, younger adults were faster than older adults on average and there was no difference in accuracy. That is, block type did not modulate behavioural markers of arousal (i.e., reaction time) or improve accuracy. While the motivation manipulation was associated with a decrease in age-related hyper-binding, this decrease was not modulated by incentive level. 


\section{Chapter 3: Discussion}

This study aimed to replicate the original hyper-binding effect as well as to explore the effect of reward motivation at encoding on hyper-binding. The first objective was achieved, with the control condition revealing an age-related recall advantage for maintained over re-arranged pairs. For the second objective, results suggest that motivation at encoding eliminated the hyperbinding effect in older adults, even at low levels of incentive. The proposed mechanism for this effect is a motivational boost in inhibitory control at encoding, which allowed older adults to selectively attend to face targets.

With its relevance to associative memory, replicating the hyper-binding effect has received increasing attention. Age-related hyper-binding suggests over-active binding in older adults, who are typically described as having binding deficits (Naveh-Benjamin, 2000). While hyper-binding and the ADH can be framed as opposing theories of age differences in binding, the current data are compatible with both accounts. Like other hyper-binding studies (Campbell \& Hasher, 2018; Campbell et al., 2010; Weeks \& Hasher, 2016), a main effect of age on name recall was found. Regardless of pair type and condition, younger adults remembered more names than older adults. This recall depended on explicit associative binding of face-name pairings from the intentional study phase. Consistent with the $\mathrm{ADH}$, older adults were less able to learn and retrieve new associations made between the face and the name. Despite this deficit in explicit face-name learning under instruction, the recall advantage for maintained pairs demonstrated by control group older adults points to increased incidental binding of taskirrelevant information to target information. Therefore, these data lend support to both increased implicit binding of task-irrelevant details and decreased explicit binding of task-relevant details. The importance of reconciling conflicting evidence for age-related changes in binding has 
theoretical significance. Simultaneous evidence for both hyper-binding and the ADH suggests that either: 1) these processes rely on distinct mechanisms, or 2) there is an underlying deficit common to over- and under-active binding that provides a more parsimonious explanation for both age-related changes. Future research should aim to uncover when, where and how this deficit or overabundance occurs.

In contrast to the increased binding demonstrated by control group older adults, motivated older adults' recall was matched across pair type. Considering the only difference between conditions occurred during the incidental encoding task, results suggest that motivated older adults did not incidentally bind task-irrelevant names to faces during the 1-back. There are theoretical grounds for considering inhibitory control as the cognitive mediator of this effect. If inhibitory control limits active representations in working memory to those that are relevant to the current goal, and goals are made more salient by attaching incentive to their attainment, then it is plausible that incentive-based motivation acts to bolster inhibition processes. In turn, participants would be more likely to selectively attend to goal-relevant faces and effectively ignore names without binding the simultaneously occurring working memory representations (Hasher et al., 1997; Hasher \& Zacks, 1988; Lustig et al., 2007). This suggests that incentivebased motivation can be harnessed to remediate inefficient inhibitory control mechanisms commonly associated with aging. The motivation manipulation here may have acted to align the "goal paths" of younger and older adults, rendering them more consistent and leading to attentional narrowing (Chiew \& Braver, 2011; Hasher \& Zacks, 1988). Investigating age-related changes in associative memory in the context of motivation lends ecological validity to highlycontrolled research findings, helping to make results more representative of real-world processes and to bridge the gap between basic and applied domains. 
The proposed mechanism through which incentives enhance inhibitory control is best conceptualized through a motivation-cognition interaction. Motivational incentives have been linked to increased dopaminergic transmission of the PFC, which is hypothesized to increase precision and persistence in representations of task goals (Bahlmann, Aarts, \& D’Esposito, 2015; Cools, 2016; Yee \& Braver, 2018). By this account, motivation boosted participants' ability to clearly and consistently activate their goal of selectively attending to target faces. This stabilizing effect on cognitive control may offset the costs (i.e., effort) that render older adults susceptible to task-irrelevant distractors at encoding (Westbrook \& Braver, 2015).

Alternatively, the reduction in hyper-binding may be due to less substantive methodological factors rather than our success in inducing a motivational state. For example, the motivated version of the 1-back task is associated with more information in general. There is an extra piece to the instructions and there are excitement and mood ratings following each block. However, by this account, participants would be keeping more in mind as opposed to experiencing attentional narrowing associated with motivation. While it is conceivable that a higher working memory load during the motivated 1-back could lead to more fragile bound representations of face-name pairs in older adults (McCormick-Huhn et al., 2017), the point values were consistent throughout blocks and did not vary trial-by-trial. Therefore, it was unlikely that participants held this information in working memory as they knew what to expect consistently throughout a given block. Additionally, there was no Age x Condition interaction on 1-back performance; older adults performed just as accurately and with similar speed in the motivated version as they did in the control version indicating no adverse effects of the added information. Moreover, the difference in older adults' recall pattern associated with the motivation manipulation is solely related to a reduction of maintained recall, with rearranged 
recall remaining virtually identical to that of the control. The specificity of this effect is more consistent with an account that selective attention at encoding was enhanced rather than participants' attention being occupied by relatively more information.

As evidenced by the non-significant Age x Pair Type x Block Type interaction, the motivational decrease in hyper-binding was not modulated by incentive level. There are a couple of possibilities that might explain this null effect. It is possible that the low-level incentive successfully motivated participants in a comparable manner to the high-level incentives. Support for this comes from the fact that the majority of participants who reported being motivated by the points during the end-of-session interview also reported that they did not feel a difference in motivation across round type. Alternatively, the lack of modulation could be due to transfer of motivation from the high-gain rounds to the low-gain rounds rather than discrete, alternating states of low and high motivation. By this account, participants were actually more motivated by the high-level incentive but this higher motivation did not dissipate during the subsequent block. This possibility is supported by the main effect of block type on arousal ratings, indicating that participants were indeed significantly more excited about their point earning following high-gain versus low-gain rounds. Introducing loss or the use of monetary rewards, for example, could be more effective in inducing block-by-block changes in motivational states (Williams et al., 2017).

There are many limitations worth noting for the current study. Firstly, our measurement of motivation was only based on self-report. A multi-method approach to measuring motivation —including the use of biological measures, for example-would enhance the construct validity of this independent variable. Second, the rewards used were hypothetical. It is arguable that the effect of our manipulation on hyper-binding may be different if tangible 
rewards such as monetary incentives or redeemable gifts were used instead of virtual points. However, the hypothesized effect was in fact achieved using only virtual points indicating that the currency of reward is not necessarily important so long as a motivational state is induced. Third, there was technically no within-subjects control condition for the motivated version of the task. The low-gain blocks were originally designed to serve this purpose. However, they were not associated with any difference in 1-back performance relative to high-gain blocks and hyperbinding of faces and names was not significantly different across block types. Fourth, according to self-reports after each block, the point manipulation did not selectively enhance excitement/motivation, as it also improved mood. Although this confound did not drive the effect in the other direction (i.e., broaden attention; Biss \& Hasher, 2011; Fredrickson, 2004), future versions should aim to selectively target motivation without influencing mood. Fifth, the sample size was relatively small for a behavioural study. While it was based on an a priori power analysis, a larger sample size would allow for a more precise estimate of the effect size for the replication and the motivational decrease in hyper-binding. Sixth and last, while younger adult participants were recruited from the community, the older adult participants were all recruited from the RSPP. These older adults are likely skewed toward higher cognitive function and overall health compared to the average community member.

Overall, the current study adds to our understanding of the associative deficit commonly identified in older adults, as well as the motivation-cognition interaction between incentives and hyper-binding. The study successfully replicated the age-related hyper-binding effect and eliminated the effect through a novel incentive manipulation. Much like value-directed encoding (Castel, Balota, \& Mccabe, 2009) reveals preserved memory selectivity in older adults at an explicit level, it appears that motivational incentives at encoding can boost memory selectivity 
implicitly as well. Future research should evaluate the threshold motivation needed for this effect, use real incentives for more controlled modulation of motivational states (but see Read, 2005), and investigate other forms of incentives that may align more closely with older adults' values, such as intrinsic motivators (e.g., performing well; Ennis, Hess, \& Smith, 2013) 


\section{Appendices}

Appendix A

DEMOGRAPHICS

Name:

Gender:

Male

Female Age:

Phone:

Email: reminder: $\mathrm{E}$ or $\mathrm{C}$ ? Handed:

EDUCATIOH

Currently Student or Non-student

Highest level of education obtained

Previous degree / diploma

Years

Area of study

Exclusion: Less than High School Diploma $(<12$ years of education)

Total years of education:

LANGUAGE

What is your first language English leamed at age

Fluent in English YES NO

Language spoken in grade school Other languages

What country were you born in Year moved to Canada

Exclusion: Not fluent in English

HEALTH

Vision

Do you wear:

GLASSES: CONTACTS

NONE

\section{Operations on your eyes?}

NO YES: Specify

Exclusion: uncorrected problems with near vision [current]

Hearing

Do you have any problems with your hearing?

$\mathrm{NO}$

YES

If YES, is your hearing corrected with a hearing aid? Specify:

Exclusion: uncorrected hearing problems that would interfere with normal speech comprehension [current]

Conditions

Have you ever had any of the following conditions?

\begin{tabular}{|c|c|c|c|c|c|c|c|}
\hline Stroke & NO & YES: & Exclusion & Learning disability & NO & YES: & ADHD? YES: Exclusion \\
\hline Tumor & NO & YES: & Brain? YES: Exclusion & Psychiatric illness & NO & YES: & Exclusion \\
\hline Neurological diseases & NO & YES: & Exclusion & Epilepsy & NO & YES: & Exclusion \\
\hline Head injury & NO & YES: & Exclusion & Cancer & NO & YES: & Last $3 \mathrm{xrs}$ ? YES: Exclusion \\
\hline Concussion & NO & YES: & Exclusion & High blood pressure & NO & YES: & Controlled? NO: Exclusion \\
\hline Depression & NO & YES: & Current? YES: Exclusion & Diabetes & NO & YES: & Controlled? $\mathrm{NO}$ : Exclusion \\
\hline Anxiety & NO & YES: & Current? YES: Exclusion & Thyroid disease & NO & YES: & Controlled? $\mathrm{NO}$ : Exclusion \\
\hline Seizure & NO & YES: & Exclusion & Serious car accident & NO & YES: & Hit head? YES: Exclusion \\
\hline Aneurysm & NO & YES: & Exclusion & Been unconscious & NO & YES: & Exclusion \\
\hline
\end{tabular}

Have you been taking any medications in the last six months 


\section{Appendix B}

Digit Symbol-Coding

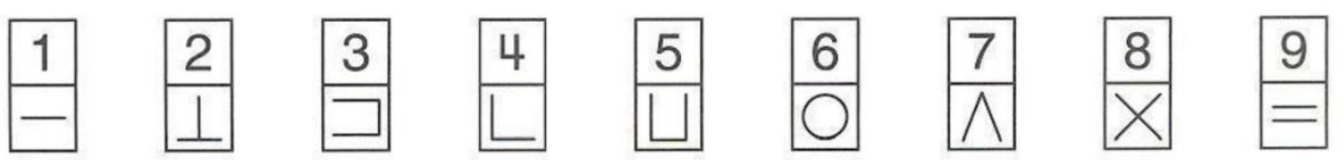

Sample Items

\begin{tabular}{|l|l|l|l|l|l|l|l|l|l|l|l|l|l|l|l|l|l|l|l|}
\hline 2 & 1 & 3 & 7 & 2 & 4 & 8 & 2 & 1 & 3 & 2 & 1 & 4 & 2 & 3 & 5 & 2 & 3 & 1 & 4 \\
\hline
\end{tabular}

\begin{tabular}{|l|l|l|l|l|l|l|l|l|l|l|l|l|l|l|l|l|l|l|l|}
\hline 5 & 6 & 3 & 1 & 4 & 1 & 5 & 4 & 2 & 7 & 6 & 3 & 5 & 7 & 2 & 8 & 5 & 4 & 6 & 3 \\
\hline
\end{tabular}

\begin{tabular}{|l|l|l|l|l|l|l|l|l|l|l|l|l|l|l|l|l|l|l|l|}
\hline 7 & 2 & 8 & 1 & 9 & 5 & 8 & 4 & 7 & 3 & 6 & 2 & 5 & 1 & 9 & 2 & 8 & 3 & 7 & 4 \\
\hline & & & & & & & & & & & & & & & & & & & \\
\hline
\end{tabular}

\begin{tabular}{|l|l|l|l|l|l|l|l|l|l|l|l|l|l|l|l|l|l|l|l|}
\hline 6 & 5 & 9 & 4 & 8 & 3 & 7 & 2 & 6 & 1 & 5 & 4 & 6 & 3 & 7 & 9 & 2 & 8 & 1 & 7 \\
\hline & & & & & & & & & & & & & & & & & & & \\
\hline
\end{tabular}

\begin{tabular}{|l|l|l|l|l|l|l|l|l|l|l|l|l|l|l|l|l|l|l|l|}
\hline 9 & 4 & 6 & 8 & 5 & 9 & 7 & 1 & 8 & 5 & 2 & 9 & 4 & 8 & 6 & 3 & 7 & 9 & 8 & 6 \\
\hline
\end{tabular}

\begin{tabular}{|l|l|l|l|l|l|l|l|l|l|l|l|l|l|l|l|l|l|l|l|}
\hline 2 & 7 & 3 & 6 & 5 & 1 & 9 & 8 & 4 & 5 & 7 & 3 & 1 & 4 & 8 & 7 & 9 & 1 & 4 & 5 \\
\hline
\end{tabular}

\begin{tabular}{|l|l|l|l|l|l|l|l|l|l|l|l|l|l|l|l|l|l|l|l|}
\hline 7 & 1 & 8 & 2 & 9 & 3 & 6 & 7 & 2 & 8 & 5 & 2 & 3 & 1 & 4 & 8 & 4 & 2 & 7 & 6 \\
\hline
\end{tabular} 


\section{Appendix C}

Digit Forward

\section{Digit Span}

\begin{tabular}{|c|c|c|c|c|}
\hline$\#$ & Digit Forward & \begin{tabular}{|l|} 
Item \\
Score \\
\end{tabular} & $\begin{array}{l}\text { Trial } \\
\text { Score }\end{array}$ & $\begin{array}{l}\# \\
\text { Digits } \\
\end{array}$ \\
\hline \multirow[t]{2}{*}{1} & $1-7$ & & & \multirow[t]{2}{*}{2} \\
\hline & $6-3$ & & & \\
\hline \multirow[t]{2}{*}{2} & $5-8-2$ & & & \multirow[t]{2}{*}{3} \\
\hline & $6-9-4$ & & & \\
\hline \multirow[t]{2}{*}{3} & $6-4-3-9$ & & & \multirow[t]{2}{*}{4} \\
\hline & $7-2-8-6$ & & & \\
\hline \multirow[t]{2}{*}{4} & $4-2-7-3-1$ & & & \multirow[t]{2}{*}{5} \\
\hline & $7-5-8-3-6$ & & & \\
\hline \multirow[t]{2}{*}{5} & $6-1-9-4-7-3$ & & & \multirow[t]{2}{*}{6} \\
\hline & $3-9-2-4-8-7$ & & & \\
\hline \multirow[t]{2}{*}{6} & $5-9-1-7-4-2-8$ & & & \multirow[t]{2}{*}{7} \\
\hline & $4-1-7-9-3-8-6$ & & & \\
\hline \multirow[t]{2}{*}{7} & $5-8-1-9-2-6-4-7$ & & & \multirow[t]{2}{*}{8} \\
\hline & $3-8-2-9-5-1-7-4$ & & & \\
\hline \multirow[t]{2}{*}{8} & $2-7-5-8-6-2-5-8-4$ & & & \multirow[t]{2}{*}{9} \\
\hline & $7-1-3-9-4-2-5-6-8$ & & & \\
\hline
\end{tabular}

Digit Backward

Forward score (0-16):

\begin{tabular}{|c|c|c|c|c|}
\hline \# & Digit Backward & $\begin{array}{l}\text { Item } \\
\text { Score }\end{array}$ & $\begin{array}{l}\text { Trial } \\
\text { Score }\end{array}$ & $\begin{array}{l}\# \\
\text { Digits }\end{array}$ \\
\hline \multirow[t]{2}{*}{1} & $2-4(4-2)$ & & & \multirow[t]{2}{*}{2} \\
\hline & $5-7(7-5)$ & & & \\
\hline \multirow[t]{2}{*}{2} & $6-2-9(9-2-6)$ & & & \multirow[t]{2}{*}{3} \\
\hline & $4-1-5(5-1-4)$ & & & \\
\hline \multirow[t]{2}{*}{3} & $3-2-7-9(9-7-2-3)$ & & & \multirow[t]{2}{*}{4} \\
\hline & $4-9-6-8(8-6-9-4)$ & & & \\
\hline \multirow[t]{2}{*}{4} & $1-5-2-8-6(6-8-2-5-1)$ & & & \multirow[t]{2}{*}{5} \\
\hline & $6-1-8-4-3(3-4-8-1-6)$ & & & \\
\hline \multirow[t]{2}{*}{5} & $5-3-9-4-1-8(8-1-4-9-3-5)$ & & & \multirow[t]{2}{*}{6} \\
\hline & $7-2-4-8-5-6(6-5-8-4-2-7)$ & & & \\
\hline \multirow[t]{2}{*}{6} & $8-1-2-9-3-6-5(5-6-3-9-2-1-8)$ & & & \multirow[t]{2}{*}{7} \\
\hline & $4-7-3-9-1-2-8(8-2-1-9-3-7-4)$ & & & \\
\hline \multirow[t]{2}{*}{7} & $9-4-3-7-6-2-5-8(8-5-2-6-7-3-4-9)$ & & & \multirow[t]{2}{*}{8} \\
\hline & $7-2-8-1-9-6-5-3(3-5-6-9-1-8-2-7)$ & & & \\
\hline
\end{tabular}

Backward score (0-14):

Total Score (0-30): 


\section{Appendix D}

Mill Hill Vocabulary Scale

Instructions

After each number (1-34) there is a word in CAPITAL letters. Below the capitalized word there are 6 words in small print, one of which means the same as the word above. Please underline the small-print word that means the same as the word in capitals.

They start off fairly easily, but rapidly get harder - we don't expect you to get them all right. But we do want you to try every one.

Even if you have no idea about the meaning of the word, please always underline one word simply guess if you don't know.

Take your own time, but don't spend ages on any one choice - just guess when you don't know.

\section{CONNECT}

$\begin{array}{ll}\text { accident } & \text { join } \\ \text { lace } & \text { bean } \\ \text { flint } & \text { field }\end{array}$

\section{PROVIDE}

harmonize commi

hurt $\quad$ supply

$\begin{array}{ll}\text { 3. STUBBORN } \\ \text { obstinate } & \text { steady } \\ \text { hopeful } & \text { hollow } \\ \text { orderly } & \text { slack }\end{array}$

5. LIBERTY

worry freedom

rich serviette

COURTEOUS

dreadful proud

truthful short

8. THRIVE

flourish try

reap natural stupid

$\begin{array}{lll} & \text { faulty } & \text { grand } \\ \text { think memory } & \text { small } & \text { exact }\end{array}$

11. DWINDLE

swindle pander

diminish wheeze

linger compare

\section{LAVISH}

unaccountable selfish romantic lawful extravagant praise

14. SURMOUNT

mountain descend

15. BOMBASTIC

democratic pompou

$\begin{array}{ll}\text { bickering cautious } \\ \text { destructive } & \text { anxious }\end{array}$

destructive anxious

unwieldy repelling
4. SCHOONER

17. ENVISAGE

activate

enfeeble regress

20. PERPETRATE

appropriate commit

propitiate deface

control pierce

23. AMULET

savoury jacket

flirtation crest

26. FECUND

esculent optative

$\begin{array}{ll}\text { profound } & \text { prolific } \\ \text { sublime } & \text { salic }\end{array}$

29. VAGARY

vagabond caprice

obscurity vulgarity

evasion fallacy

32. NUGATORY

inimitable adamant

$\begin{array}{lll}\text { 16. RECUMBENT } & \text { sublime } & \text { contrary } \\ \text { fugitive cumbersome } & \text { numismatic } & \text { trifling }\end{array}$
18. TRUMPERY

etiquette highest

amusement final disguise gloat

21. LEVITY

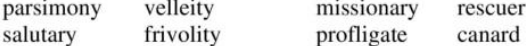

alacrity tariff regicide farrago

24. QUERULOUS

astringent fearfu

petulant curious

inquiring spurious

25. TEMERITY

impermanence rashnes

nervousness stability

punctuality submissiveness

27. ABNEGATE

28. TRADUCE

suspend establish

misrepresent conclude

30. SPECIOUS

fallacious coeval

$\begin{array}{ll}\text { palatial } & \text { typical } \\ \text { nutritious } & \text { flexible }\end{array}$

33. ADUMBRATE

foreshadow protect

eradicate

laborate approach

31. SEDULOUS

rebellious dilatory

complainant diligent

seductive credulous

34. MINATORY

implacable diminutive

belittling quiescent

Page 1

Page 2 


\section{Appendix E}

\section{DASS $_{21}$}

Please read each statement and circle a number $0,1,2$ or 3 which indicates how much the statement applied to you over the past week. There are no right or wrong answers. Do not spend too much time on any statement.

The rating scale is as follows:

0 Did not apply to me at all

1 Applied to me to some degree, or some of the time

2 Applied to me to a considerable degree, or a good part of time

3 Applied to me very much, or most of the time

1 I found it hard to wind down

2 I was aware of dryness of my mouth

3 I couldn't seem to experience any positive feeling at all

4 I experienced breathing difficulty (eg, excessively rapid breathing, breathlessness in the absence of physical exertion)

5 I found it difficult to work up the initiative to do things

6 I tended to over-react to situations

7 I experienced trembling (eg, in the hands)

8 I felt that I was using a lot of nervous energy

9 I was worried about situations in which I might panic and make a fool of myself

10 I felt that I had nothing to look forward to

11 I found myself getting agitated

12 I found it difficult to relax

13 I felt down-hearted and blue

14 I was intolerant of anything that kept me from getting on with what I was doing

15 I felt I was close to panic

16 I was unable to become enthusiastic about anything

17 I felt I wasn't worth much as a person

18 I felt that I was rather touchy

19 I was aware of the action of my heart in the absence of physical exertion (eg, sense of heart rate increase, heart missing a beat)

$\begin{array}{llll}0 & 1 & 2 & 3 \\ 0 & 1 & 2 & 3 \\ 0 & 1 & 2 & 3 \\ 0 & 1 & 2 & 3 \\ 0 & 1 & 2 & 3 \\ 0 & 1 & 2 & 3 \\ 0 & 1 & 2 & 3 \\ 0 & 1 & 2 & 3 \\ 0 & 1 & 2 & 3 \\ 0 & 1 & 2 & 3 \\ 0 & 1 & 2 & 3 \\ 0 & 1 & 2 & 3 \\ 0 & 1 & 2 & 3 \\ 0 & 1 & 2 & 3 \\ 0 & 1 & 2 & 3 \\ 0 & 1 & 2 & 3 \\ 0 & 1 & 2 & 3 \\ 0 & 1 & 2 & 3 \\ 0 & 1 & 2 & 3 \\ 0 & 1 & 2 & 3 \\ 0 & 1 & 2 & 3\end{array}$

20 I felt scared without any good reason

21 I felt that life was meaningless 


\section{Appendix F}

\section{The PANAS}

This scale consists of a number of words that describe different feelings and emotions. Read each item and then circle the appropriate answer next to the word. Indicate to what extent you feel this way right now at this moment.

Use the following scale to record your answers:

\begin{tabular}{|c|c|c|c|c|}
\hline 1 & 2 & 3 & 4 & 5 \\
\hline $\begin{array}{c}\text { Very slightly or } \\
\text { not at all }\end{array}$ & A little & Moderately & Quite a bit & Extremely \\
\hline
\end{tabular}

\begin{tabular}{llllll} 
1. Interested & 1 & 2 & 3 & 4 & 5 \\
\hline 2. Distressed & 1 & 2 & 3 & 4 & 5 \\
\hline 3. Excited & 1 & 2 & 3 & 4 & 5 \\
\hline 4. Upset & 1 & 2 & 3 & 4 & 5 \\
\hline 5. Strong & 1 & 2 & 3 & 4 & 5 \\
\hline 6. Guilty & 1 & 2 & 3 & 4 & 5 \\
\hline 7. Scared & 1 & 2 & 3 & 4 & 5 \\
\hline 8. Hostile & 1 & 2 & 3 & 4 & 5 \\
\hline 9. Enthusiastic & 1 & 2 & 3 & 4 & 5 \\
\hline 10. Proud & 1 & 2 & 3 & 4 & 5 \\
\hline 11. Irritable & 1 & 2 & 3 & 4 & 5 \\
\hline 12. Alert & 1 & 2 & 3 & 4 & 5 \\
\hline 13. Ashamed & 1 & 2 & 3 & 4 & 5 \\
\hline 14. Inspired & 1 & 2 & 3 & 4 & 5 \\
\hline 15. Nervous & 1 & 2 & 3 & 4 & 5 \\
\hline 16. Determined & 1 & 2 & 3 & 4 & 5 \\
\hline 17. Attentive & 1 & 2 & 3 & 4 & 5 \\
\hline 18. Jittery & 1 & 2 & 3 & 4 & 5 \\
\hline 19. Active & & & 4 & 5 \\
\hline 20. Afraid & 1 & 3 & 4 & 5 \\
\hline & 1 & 2 & 3 & 5 \\
\hline
\end{tabular}




\section{Appendix G}

\section{BIS/BAS}

Each item of this questionnaire is a statement that a person may either agree with or disagree with. For each item, indicate how much you agree or disagree with what the item says. Choose only one response to each statement. Please be as accurate and honest as you can be. Respond to each item as if it were the only item. That is, don't worry about being "consistent" in your responses. Choose from the following four response options:

$1=$ very true for me

2 = somewhat true for me

3 = somewhat false for me

4 = very false for me

1. A person's family is the most important thing in life.

$\begin{array}{rlll}\begin{array}{c}\text { Very true } \\ \text { for me }\end{array} & & \begin{array}{c}\text { Very false } \\ \text { for me }\end{array} \\ 1 & 2 & 3 & 4\end{array}$

2. Even if something bad is about to happen to me, I rarely experience fear or nervousness.

$\begin{array}{llll}1 & 2 & 3 & 4\end{array}$

3. I go out of my way to get things I want.

$\begin{array}{llll}1 & 2 & 3 & 4\end{array}$

4. When I'm doing well at something I love to keep at it.

$\begin{array}{llll}1 & 2 & 3 & 4\end{array}$

5. I'm always willing to try something new if I think it will be fun.

$\begin{array}{llll}1 & 2 & 3 & 4\end{array}$

6. How I dress is important to me.

$\begin{array}{llll}1 & 2 & 3 & 4\end{array}$

7. When I get something I want, I feel excited and energized.

$\begin{array}{llll}1 & 2 & 3 & 4\end{array}$

8. Criticism or scolding hurts me quite a bit.

9. When I want something I usually go all-out to get it.

10. I will often do things for no other reason than that they might be fun.

$1 \quad 2 \quad 3 \quad 4$

$\begin{array}{llll}1 & 2 & 3 & 4\end{array}$

11. It's hard for me to find the time to do things such as get a haircut.

$\begin{array}{llll}1 & 2 & 3 & 4\end{array}$

$\begin{array}{llll}1 & 2 & 3 & 4\end{array}$

12. If I see a chance to get something I want I move on it right away.

$1 \quad 2 \quad 3 \quad 4$

13. I feel pretty worried or upset when I think or know somebody is angry at me.

$1 \quad 2 \quad 3 \quad 4$

14. When I see an opportunity for something I like I get excited right away.

$\begin{array}{llll}1 & 2 & 3 & 4\end{array}$

15. I often act on the spur of the moment.

$\begin{array}{llll}1 & 2 & 3 & 4\end{array}$

16. If I think something unpleasant is going to happen I usually get pretty "worked up."

$\begin{array}{llll}1 & 2 & 3 & 4\end{array}$

17. I often wonder why people act the way they do.

$\begin{array}{llll}1 & 2 & 3 & 4\end{array}$

18. When good things happen to me, it affects me strongly.

$\begin{array}{llll}1 & 2 & 3 & 4\end{array}$

19. I feel worried when I think I have done poorly at something important.

$\begin{array}{llll}1 & 2 & 3 & 4\end{array}$

20. I crave excitement and new sensations.

$\begin{array}{llll}1 & 2 & 3 & 4\end{array}$

21. When I go after something I use a "no holds barred" approach.

$\begin{array}{llll}1 & 2 & 3 & 4\end{array}$

22. I have very few fears compared to my friends.

$\begin{array}{llll}1 & 2 & 3 & 4\end{array}$

23 . It would excite me to win a contest.

$\begin{array}{llll}1 & 2 & 3 & 4\end{array}$

24. I worry about making mistakes.

$1 \quad 2 \quad 3 \quad 4$ 
Appendix $\mathrm{H}$

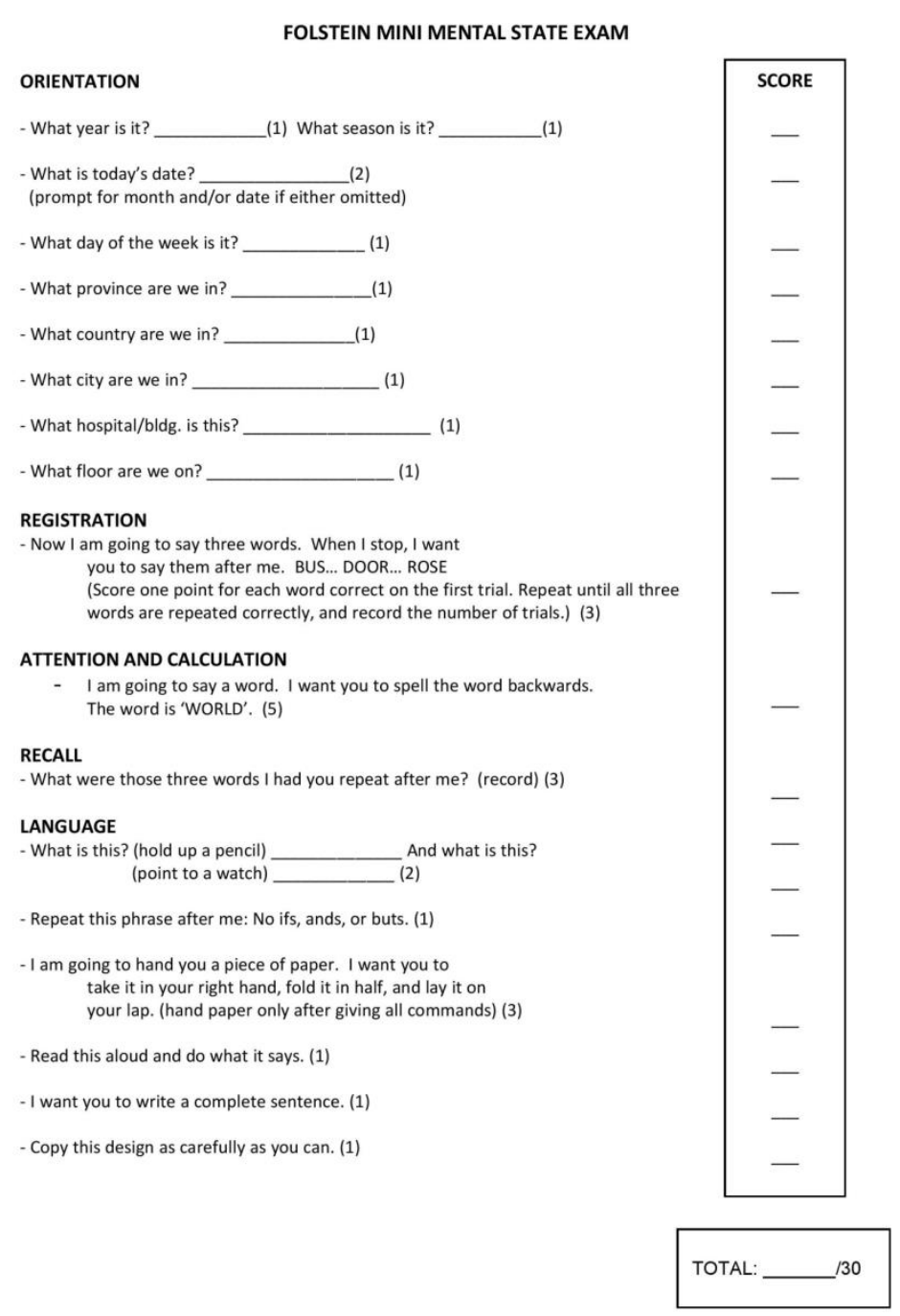

\section{Close Your Eyes}

Page 1

Page 2 


\section{Appendix I}

\section{AWARENESS QUESTIONNAIRE}

**Motivated condition only:

1. Did you feel motivated by the points in the first task?

2. Did you feel more motivated in the high- versus the low-gain rounds?

Both Conditions:

Part 1: Did you suspect that your memory would be tested?

- "no"

- "yes"

Part 2:

1. Did you notice a connection between any of the tasks you did?

- If "no", UNAWARE

- If "yes", then ask the following:

2. What did you notice?

3. When did you notice it and how did you notice?

4. Did you consciously try to use or avoid using the words you saw in the first task as responses to the last task?
AWARE
UNAWARE 


\section{References}

Amer, T., \& Hasher, L. (2014). Conceptual processing of distractors by older but not younger adults. Psychological Science, 25, 2252-2258.

Bahlmann, J., Aarts, E., \& D’Esposito, M. (2015). Influence of Motivation on Control Hierarchy in the Human Frontal Cortex. Journal of Neuroscience, 35, 3207-3217.

Biss, R. K., \& Hasher, L. (2011). Delighted and distracted: Positive affect increases priming for irrelevant information. Emotion, 11, 1474-1478.

Biss, R. K., Ngo, K. W., Hasher, L., Campbell, K. L., \& Rowe, G. (2013). Distraction can reduce age-related forgetting. Psychological Science, 24, 448-455.

Bradley, M., \& Lang, P. J. (1994). Measuring Emotion: The Self-Assessment Semantic Differential Manikin and the. Journal of Behavior Therapy and Experimental Psychiatry, $25,49-59$.

Braver, T. S. (2012). The variable nature of cognitive control: A dual-mechanisms framework. Trends in Cognitive Sciences, 16, 106-113.

Braver, T. S., \& Barch, D. M. (2002). A theory of cognitive control , aging cognition , and neuromodulation, 26, 809-817.

Braver, T. S., Krug, M. K., Chiew, K. S., Kool, W., Westbrook, J. A., Clement, N. J., ... Somerville, L. H. (2014). Mechanisms of motivation-cognition interaction: challenges and opportunities. Cognitive, Affective \& Behavioral Neuroscience, 14, 443-472.

Cacioppo, J. T., Berntson, G. G., Bechara, A., Tranel, D., \& Hawkley, L. C. (2011). Could an aging brain contribute to subjective well-being?: The value added by a social neuroscience perspective. Social Neuroscience, 1-23.

Campbell, K. L., Grigg, O., Saverino, C., Churchill, N., \& Grady, C. L. (2013). Age differences 
in the intrinsic functional connectivity of default network subsystems. Frontiers in Aging Neuroscience, 5, 1-12.

Campbell, K. L., \& Hasher, L. (2018). Hyper-binding only apparent under fully implicit test conditions. Psychology and Aging, 33, 176-181.

Campbell, K. L., Hasher, L., \& Thomas, R. C. (2010). Hyper-binding: a unique age effect. Psychological Science, 21, 399-405.

Campbell, K. L., Trelle, A., \& Hasher, L. (2014). Hyper-binding across time: age differences in the effect of temporal proximity on paired-associate learning. Journal of Experimental Psychology. Learning, Memory, and Cognition, 40, 293-9.

Campbell, K. L., Zimerman, S., Healey, M. K., Lee, M., \& Hasher, L. (2012). Age Differences in Visual Statistical Learning. Psychology and Aging, 27, 650-656.

Carstensen, L. L., \& DeLiema, M. (2018). The positivity effect: a negativity bias in youth fades with age. Current Opinion in Behavioral Sciences, 19, 7-12.

Carstensen, L. L., Fung, H. H., \& Charles, S. T. (2003). Socioemotional selectivity theory and emotion regulation in the second half of life. Motivation and Emotion, 27, 103-123.

Carstensen, L. L., Isaacowitz, D. M., Charles, S. T., Prakash, R. S., De Leon, A. A., Patterson, B., ... Janssen, A. L. (1999). Taking Time Seriously. The American Psychologist, 54, 165181.

Carver, C. S., \& White, T. L. (1994). Behavioral inhibition, behavioral activation, and affective responses to impending reward and punishment: The BIS/BAS Scales. Journal of Personality and Social Psychology, 67, 319-333.

Castel, A. D., Balota, D. A., \& Mccabe, D. P. (2009). Aging, Memory Efficiency and the Strategic Control of Attention at Encoding: Impairments of Value-Directed Remembering 
in Alzheimer's Disease. Neuropsychology, 23, 297-306.

Castel, A. D., Benjamin, A. S., Craik, F. I. M., \& Watkins, M. J. (2002). The effects of aging on selectivity and control in short-term recall. Memory \& Cognition, 30, 1078-1085.

Castel, A. D., Friedman, M. C., McGillivray, S., Flores, C. C., Murayama, K., Kerr, T., \& Drolet, A. (2016). I owe you: age-related similarities and differences in associative memory for gains and losses. Aging, Neuropsychology, and Cognition, 23, 549-565.

Cheke, L. G. (2016). What-where-when memory and encoding strategies in healthy aging. Learning \& Memory, 23, 121-126.

Chiew, K. S., \& Braver, T. S. (2011). Positive affect versus reward: Emotional and motivational influences on cognitive control. Frontiers in Psychology, 2, 1-10.

Cohen, M. S., Rissman, J., Suthana, N. A., Castel, A. D., \& Knowlton, B. J. (2014). Value-based modulation of memory encoding involves strategic engagement of fronto-temporal semantic processing regions. Cognitive, Affective \& Behavioral Neuroscience, 14, 578-592.

Cools, R. (2016). The costs and benefits of brain dopamine for cognitive control. Wiley Interdisciplinary Reviews. Cognitive Science, 7, 317-329.

Cowan, N. (1988). Evolving Conceptions of Memory Storage, Selective Attention, and their Mutual Constraints Within the Human Information-Processing System.

Devitt, A. L., \& Schacter, D. L. (2016). False memories with age: Neural and cognitive underpinnings. Neuropsychologia, 91, 346-359.

Diamond, A. (2013). Executive Functions. Annual Review of Psychology, 64, 135-168.

Ennis, G. E., Hess, T. M., \& Smith, B. T. (2013). The impact of age and motivation on cognitive effort: Implications for cognitive engagement in older adulthood. Psychology and Aging, $28,495-504$. 
Eriksen, B. A., \& Eriksen, C. W. (1974). Effects of noise letters upon the identification of a target letter in a nonsearch task. Perception \& Psychophysics, 16, 143-149.

Folstein, M. F., Folstein, S. E., \& McHugh, P. R. (1975). "Mini-mental state”. A practical method for grading the cognitive state of patients for the clinician. Journal of Psychiatric Research, 12, 189-198.

Fredrickson, B. L. (2004). The broaden-and-build theory of positive emotions. The Royal Society, 359, 1367-1377.

Geraci, L. (2006). A Test of the Frontal Lobe Functioning Hypothesis of Age Deficits in Production Priming. Neuropsychology, 20, 539-548.

Giesen, C., Eberhard, M., \& Rothermund, K. (2015). Loss of attentional inhibition in older adults-Does it really exist? An experimental dissociation of inhibitory and memory retrieval processes. Psychology and Aging, 30, 220-231.

Gomez, P., Ratcliff, R., \& Perea, M. (2007). A model of the go/no-go task. Journal of Experimental Psychology. General, 136, 389-413.

Grady, C. L. (2008). Cognitive Neuroscience of Aging. Annals of the New York Academy of Sciences, 144, 127-144.

Gruber, M. J., Ritchey, M., Wang, S. F., Doss, M. K., \& Ranganath, C. (2016). Post-learning Hippocampal Dynamics Promote Preferential Retention of Rewarding Events. Neuron, 89, $1110-1120$.

Hamm, V. P., \& Hasher, L. (1992). Age and the availability of inferences. Psychology and Aging.

Hasher, L., Lustig, C., \& Zacks, R. (2008). Inhibitory Mechanisms and the Control of Attention. Variation in Working Memory. 
Hasher, L., Quig, M. B., \& May, C. P. (1997). Inhibitory control over non-longer relevant information : Adult age differences. Memory and Cognition, 25, 286-295.

Hasher, L., Stoltzfus, E. R., Zacks, R. T., \& Rypma, B. (1991). Age and inhibition. Journal of Experimental Psychology. Learning, Memory, and Cognition, 17, 163-169.

Hasher, L., \& Zacks, R. T. (1988). Working Memory, Comprehension, and Aging: A Review and a New View. Psychology of Learning and Motivation - Advances in Research and Theory, 22, 193-225.

Hasher, L., Zacks, R. T., \& May, C. P. (1999). Inhibitory control, circadian arousal, and age. Attention and Performance XVII, Cognitive Regulation of Performance: Interaction of Theory and Application, 653-675.

James, T., Strunk, J., Arndt, J., \& Duarte, A. (2016). Age-related deficits in selective attention during encoding increase demands on episodic reconstruction during context retrieval: An ERP study. Neuropsychologia, 86, 66-79.

Kalenzaga, S., Lamidey, V., Ergis, A. M., Clarys, D., \& Piolino, P. (2016). The Positivity Bias in Aging: Motivation or Degradation? Emotion, 16, 602-610.

Kennedy, K. M., Hope, K., \& Raz, N. (2009). Life span adult faces: Norms for age, familiarity, memorability, mood, and picture quality. Experimental Aging Research, 35, 268-275.

Kennedy, Q., Mather, M., \& Carstensen, L. L. (2004). The role of motivation in the age-related positive bias in autobiographical memory. Psychological Science, 15, 208-214.

Labouvie-Vief, G., Grühn, D., \& Studer, J. (2010). Dynamic integration of emotion and cognition: Equilibrium regulation in development and aging. The Handbook of Life-Span Development.

Logan, G. D. (2002). An Instance Theory of Attention and Memory. Psychological Review, 109, 
$376-400$.

Lovibond, P. F., \& Lovibond, S. H. (1995). The structure of negative emotional states:

Comparison of the Depression Anxiety Stress Scales (DASS) with the Beck Depression and Anxiety Inventories. Behavioral Research and Therapy, 33, 335-343.

Lustig, C., Hasher, L., \& Zacks, R. T. (2007). Inhibitory deficit theory: Recent developments in a "new view." Inhibition in Cognition, 145-162.

Mather, M., Canli, T., English, T., Whitfield, S., Wais, P., Gabrieli, J. D. E., ... Ochsner, K. (2004). Amygdala Responses to Emotionally Valenced Stimuli in Older and Younger Adults. Psychological Science, 15, 259-263.

Mather, M., \& Carstensen, L. L. (2003). Aging and attentional biases for emotional faces. Psychological Science, 14, 409-415.

Mather, M., \& Carstensen, L. L. (2005). Aging and motivated cognition: The positivity effect in attention and memory. Trends in Cognitive Sciences, 9, 496-502.

Mather, M., \& Harley, C. W. (2016). The Locus Coeruleus: Essential for Maintaining Cognitive Function and the Aging Brain. Trends in Cognitive Sciences, 20, 214-226.

Mather, M., \& Knight, M. (2005). Goal-directed memory: The role of cognitive control in older adults' emotional memory. Psychology and Aging, 20, 554-570.

Mather, M., \& Schoeke, A. (2011). Positive outcomes enhance incidental learning for both younger and older adults. Frontiers in Neuroscience, 5, 1-10.

McCormick-Huhn, J. M., Chen, H., Wyble, B. P., \& Dennis, N. A. (2017). Using Attribute Amnesia to Test the Limits of Hyperbinding and Associative Deficits in Working Memory. Psychology and Aging, 33, 165-175.

Minear, M., \& Park, D. C. (2004). A lifespan database of adult facial stimuli. Behavior Research 
Methods, Instruments, and Computers, 36, 630-633.

Naveh-Benjamin, M. (2000). Adult age differences in memory performance: Tests of an Associative Deficit hypothesis. Journal of Experimental Psychology: Learning, Memory, and Cognition, 26, 1170-1187.

Pettigrew, C., \& Martin, R. C. (2014). Cognitive declines in healthy aging: Evidence from multiple aspects of interference resolution. Psychology and Aging, 29, 187-204.

Ptak, R. (2012). The Frontoparietal Attention Network of the Human Brain : Action, Saliency, and a Priority Map of the Environment. The Neuroscientist, 18, 502-515.

Raven, J. C. (1982). Revised Manual for Raven's Progressive Matrices and Vocabulary Scale. Windsor, England: NFER Nelson.

Read, D. (2005). Monetary incentives, what are they good for? Journal of Economic Methodology, 12, 265-276.

Redick, T. S., \& Lindsey, D. R. B. (2013). Complex span and n -back measures of working memory : A meta-analysis. Psychonomic Bulletin \& Review, 20, 1102-1113.

Reed, A. E., \& Carstensen, L. L. (2012). The theory behind the age-related positivity effect. Frontiers in Psychology, 3, 1-9.

Reed, A. E., Chan, L., \& Mikels, J. A. (2014). Meta-analysis of the age-related positivity effect: Age differences in preferences for positive over negative information. Psychology and Aging, 29, 1-15.

Rhodes, M. G., \& Anastasi, J. S. (2012). The own-age bias in face recognition: A meta-analytic and theoretical review. Psychological Bulletin, 138, 146-174.

Rowe, G., Valderrama, S., Hasher, L., \& Lenartowicz, A. (2006). Attentional Disregulation: A Benefit for Implicit Memory. Psychology and Aging, 21, 826-830. 
Spaniol, J., Bowen, H. J., Wegier, P., \& Grady, C. (2015). Neural responses to monetary incentives in younger and older adults. Brain Research, 1612, 70-82.

Spaniol, J., Schain, C., \& Bowen, H. J. (2014). Reward-Enhanced Memory in Younger and Older Adults. Journals of Gerontology, Series B: Psychological Sciences and Social Sciences, 69, 730-740.

Spaniol, J., Voss, A., \& Grady, C. L. (2008). Aging and Emotional Memory: Cognitive Mechanisms Underlying the Positivity Effect. Psychology and Aging, 23, 859-872.

Stroop, J. R. (1935). Studies of interference in serial verbal reactions. Journal of Experimental Psychology, 18, 643-662.

Tipper, S. P., \& Driver, J. (1988). Negative priming between pictures and words in a selective attention task: Evidence for semantic processing of ignored stimuli. Memory \& Cognition, $16,64$.

Watson, D., Clark, L. A., \& Tellegen, A. (1988). Development and Validation of Brief Measures of Positive and Negative Affect: The PANAS Scales. Journal of Personality and Social Psychology, 54, 1063-1070.

Wechsler, D. (1997). WAIS-III: Administration and scoring manual. San Antonio, TX: The Psychological Association.

Weeks, J. C., Biss, R. K., Murphy, K. J., \& Hasher, L. (2016). Face-name learning in older adults: a benefit of hyper-binding. Psychonomic Bulletin \& Review, 23, 1559-1565.

Weeks, J. C., \& Hasher, L. (2016). Divided attention reduces resistance to distraction at encoding but not retrieval. Psychonomic Bulletin \& Review.

West, R., \& Alain, C. (2000). Age-related decline in inhibitory control contributes to the increased Stroop effect in older adults Age-related decline in inhibitory control contributes 
to the increased Stroop effect observed in older adults, 37, 179-189.

Westbrook, A., \& Braver, T. S. (2015). Cognitive effort: A neuroeconomic approach. Cognitive, Affective and Behavioral Neuroscience, 15, 395-415.

Williams, B. R., Ponesse, J. S., Schachar, R. J., Logan, G. D., \& Tannock, R. (1999).

Development of inhibitory control across the life span. Developmental Psychology, 35, $205-213$.

Williams, R. S., Kudus, F., Dyson, B. J., \& Spaniol, J. (2017). Transient and sustained incentive effects on electrophysiological indices of cognitive control in younger and older adults. Cognitive Affective \& Behavioral Neuroscience, 313-330.

Yee, D. M., \& Braver, T. S. (2018). Interactions of motivation and cognitive control. Current Opinion in Behavioral Sciences, 19, 83-90. 